\title{
NISTIR 88-3855
}

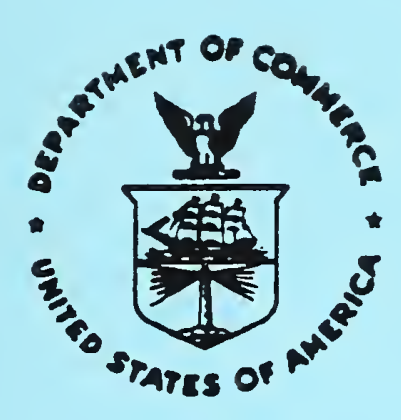

Integral Mass Barāñces
and Pulse Injection
Tracer Techniques

James Axley and Andrew Persily

U.S. DEPARTMENT OF COMMERCE

National Institute of Standards and Technology

(Formerly National Bureau of Standards)

National Engineering Laboratory

Center for Building Technology

Building Environment Division

Gaithersburg, MD 20899

October 1988

Sponsored by

U.S. Department of Energy

National Institute of Standards and Technology

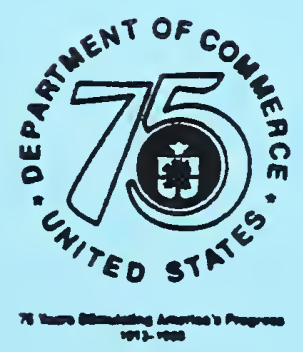



NISTIR $\quad 88-3855$

\section{INTEGRAL MASS BALANCES}

AND

PULSE INJECTION TRACER TECHNIQUES

James Axley

Andrew Persily

U.S. DEPARTMENT OF COMMERCE

National Institute of Standards and Technology

National Engineering Laboratory

Center for Building Technology

Building Environment Division

October 1988

Sponsored by:

U.S. Department of Energy

U.S. National Institute of Standards and Technology 



\begin{abstract}
Tracer gas techniques for measuring airflow rates in building systems are considered. These techniques are classified in terms of tracer gas injection strategy employed and mass balance relationships used to analyze measured tracer concentration data. The discussion focuses on one class of tracer techniques - the pulse injection techniques - based upon pulse injection strategies and integral mass balance relationships. These pulse injection techniques have not been commonly used in the past yet they provide practically useful means for the determination of airflow rates in building systems. Pulse injection techniques are presented for measuring airflows in ducts, and for studying single-zone and multi-zone building airflow systems. Experimental procedures for these three cases are discussed, and preliminary results from field applications of these techniques are presented. The possibility of flow variation is accounted for in all cases, and the sensitivity of the single-zone pulse injection technique to these flow variations is compared to that of the single-zone constant injection technique. This comparison leads to integral formulations of the constant injection technique for duct, singlezone, and multi-zone situations that may provide means to improve the accuracy of the commonly used constant injection tracer technique.
\end{abstract}

KEY WORDS: airflow, infiluration, integral mass balances, tracer gas techniques, ventilation 


\section{ACKNOWLEDGEMENT}

This work was supported, in part, by the U. S. Department of Energy through the Interagency Agreement: IAG: DE AI01-86-CD 21013 Amendment Number 4, with the remaining funding by the National Institute of Standards and Technology.

This report was presented at the 9 th Air Infiltration and Ventilation Centre Conference, Effective Ventilation, held at Novotel Gent, Belgium, 12-15 September 1988, and is published in the conference proceedings. 
ABSTRACT
ACKNOWLEDGEMENT
CONTENTS
LIST OF TABLES \& FIGURES
NOMENCLATURE

INTRODUCTION . . . . . . . . . . . . . . . . . . . . 1

Tracer Injection Strategy . . . . . . . . . . . . . . . . . . . . . . 1

Mass Balance Relations . . . . . . . . . . . . . . . . . . . . 1

Classification of Tracer Techniques . . . . . . . . . . . . . . . . . . 2

Pulse Injection Technique . . . . . . . . . . . . . . . . . . . . . 3

DUCT PULSE TECHNIQUE . . . . . . . . . . . . . . . . 4

Theory. . . . . . . . . . . . . . . . . 4

Experimental Procedures . . . . . . . . . . . . . . 5

Measured Results . . . . . . . . . . . . . . . . . . . . . . . . 6

BUILDING PULSE TECHNIQUES . . . . . . . . . . . . 6

Single Zone Pulse Technique ............. 7

Theory . . . . . . . . . . . . . . . 7

Experimental Procedures . . . . . . . . . . . . . . 8

Measured Results . . . . . . . . . . . . . . . . . . . . . . 9

Comparison of Single-Zone Pulse and Constant Injection Techniques 9

Theory: Constant Injection Technique . . . . . . . . . . . . . . . 9

Harmonic Flow Variation . . . . . . . . . . . . . . . . . . . . 11

Pulse Injection Response: . . . . . . . . . . . . . . . . . . 11

Constant Injection Response: . . . . . . . . . . . . . . . . . 11

Multi-Zone Theory . . . . . . . . . . . . . . . . 14

Singularity and Conditioning of the Inverse Formulations . . . . . . . 19

Conservation of Air Mass Flow . . . . . . . . . . . . . . . . . 20

The Tracer and Integral Tracer Matrices . . . . . . . . . . . . . . . 21

Multi-Zone Pulse Tracer Injection Strategy . . . . . . . . . . . . . 21

Nonsingularity of the Integral Concentration Matrix . . . . . . . . 22

Constant Injection Tracer Injection Strategy . . . . . . . . . . . . . 23

Nonsingularity of the Concentration Matrix . . . . . . . . . . . . 23

Integral Constant Injection Technique . . . . . . . . . . . . . . . 23

Solution of the Inverse Analysis Equations and Error Evaluation . . . . . 24

Application of the Multi-Zone Pulse Injection Technique . . . . . 25

Measurement Method . . . . . . . . . . . . . . . . 25

Measured Results: NBS Office Building Study . . . . . . . . . . . . 26

CONCLUSION ........................ 30

REFERENCES . . . . . . . . . . . . . . . . . . 30 


\section{LIST OF TABLES \& FIGURES}

Page

Table 1 Classification of Tracer Techniques . . . . . . . . . . . . . . . . . 2

Fig. 1 Duct Pulse Injection Technique . . . . . . . . . . . . . . . . . . 4

Fig. 2 Comparison of Duct-Pulse and Hot-Wire Measurements . . . . . . . . . 6

Fig. 3 Single Zone Pulse Injection Technique . . . . . . . . . . . . . . . . 7

Fig. 4 Single-Zone Constant Injection Technique . . . . . . . . . . . . . . 10

Fig. 5 Pulse Injection Response for $\alpha=1.0$. . . . . . . . . . . . . . . . . 12

Fig. 6 Pulse Injection Response for $\alpha=-1.0$. . . . . . . . . . . . . . . . 12

Fig. 7 Constant Injection Response for $\alpha=1.0 \quad$. . . . . . . . . . . . . . . . . 13

Fig. 8 Ratio of Constant Injection Estimated Flow Rate to Mean Flow Rate . . . . 14 for Long Averaging Time Intervals

Fig. 9 A Three-Building-Zone Idealization . . . . . . . . . . . . . . . . 15

Fig. 10 Multi-Zone Pulse Injection Technique . . . . . . . . . . . . . . . 22

Fig. 11 Multi-Zone Constant Injection Technique . . . . . . . . . . . . . . 23

Fig. 12 Multi-Zone Integral Constant Injection Technique . . . . . . . . . . . 24

Fig. 13 Simplified Section of an Individual Floor of Tower . . . . . . . . . . . . . 26

Fig. 14 Office Tower Three-Zone Idcalization and Results for 12/1/87 . . . . . . . 27

Fig. 15 Comparison of Measured and Predicted Response to Pulse Injections . . . . 28

Fig. 16 Individual Floor Idealization and Results for Repeated Tests of 12/17/87 . . . 29 


\section{NOMENCLATURE}

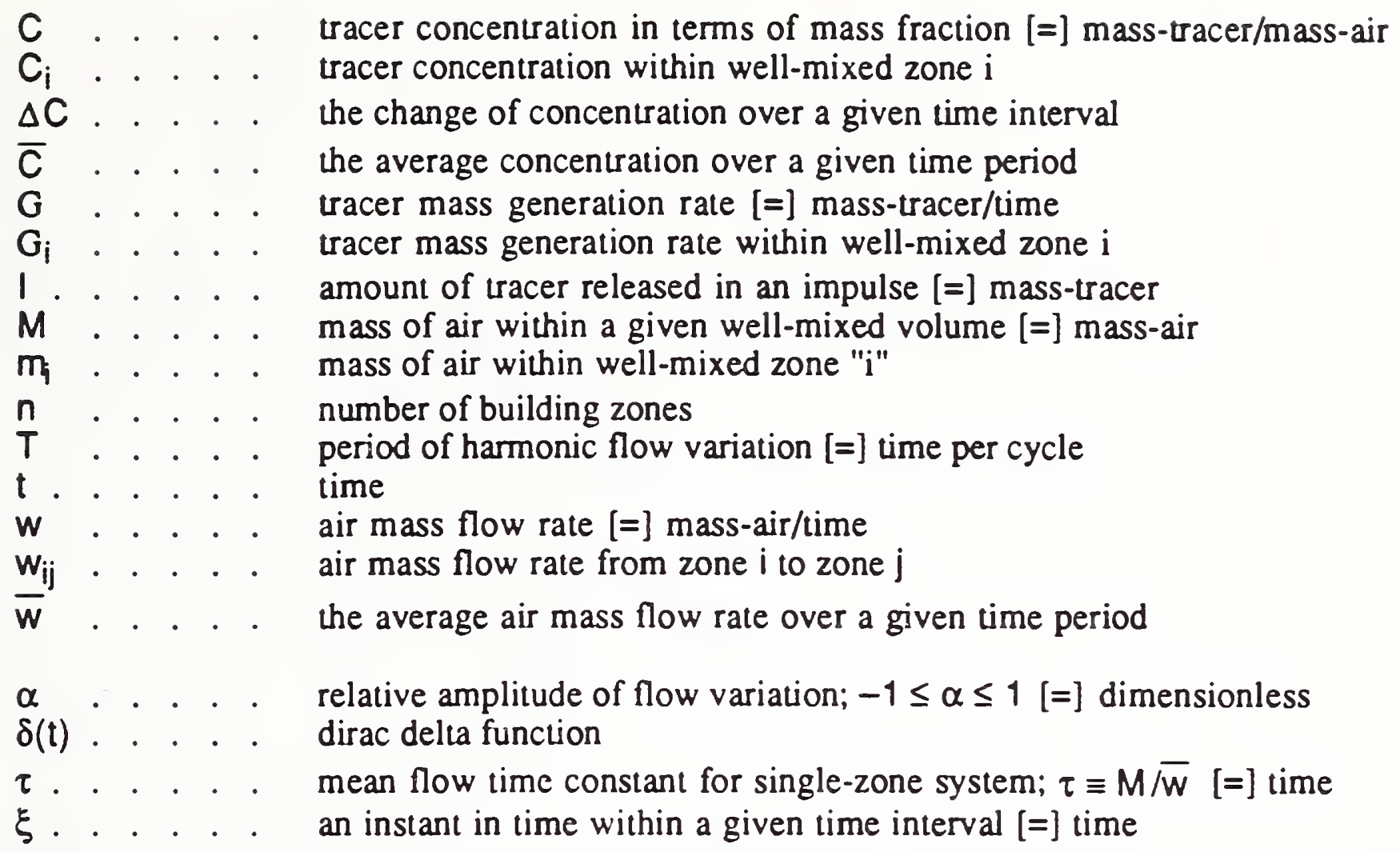

Vectors and Matrices
\{C\}. . . vector of zone concentrations
[C] . . . . instantaneous concentration matrix
[C] . . . integral concentration matrix
$\left\{\mathbf{e}_{i}\right\}$. . . . the ith unit vector with element $i$ equal to 1 and all other elements zero
\{G\} . . . . vector of zone generation rates
[M] . . . . system mass matrix
[T] . . . . instantaneous tracer rate matrix
$\left[\int \mathrm{T}\right] . . \quad$. . integral tracer matrix
[W] . . . . system mass transport rate matrix
$[\tau] \equiv[M]^{-1}[\mathrm{~W}]$ steady flow system state matrix

Following subscripts identify well-mixed zones with " 0 " used to identify, specifically, the exterior environment. Following superscripts are used to identify data sets. Leading superscripts are used to identify tracer species. 


\section{INTRODUCTION}

Indoor air quality and energy use in buildings are both closely related to airflow into, out of, and within a building system. Consequently, indoor air quality and building energy analysis both depend critically upon obtaining complete and detailed information about these airflows. In some special cases these flows will be substantially determined by the design of the HVAC system, but, more often, due to uncertainties in the actual performance of the HVAC system, additional uncertainties in envelope infiltration, and the inherently complex nature of inter-zone airflows, these flows will be unknown. In these cases one may attempt to determine these flows using network flow analysis methods [Walton 85, Axley 87] or, for existing buildings, using tracer gas measurement techniques.

Perera [82] and Lagus [85] provide comprehensive reviews of existing tracer gas techniques for measuring airflows in buildings. This paper reconsiders these tracer techniques from the point of view of integral mass balance relationships. In this section we classify tracer techniques by the tracer gas injection strategy employed to excite the building airflow system and by the form of the mass balance relations used to reduce measured tracer concentration data to determine flows. It is argued that the tracer techniques based upon integral mass balance relations - integral tracer techniques - have been largely ignored and need to be studied more thoroughly. We then focus consideration on one class of techniques based upon integral mass balance relations, the pulse injection techniques. A second integral tracer technique, the constant injection integral technique, is briefly presented in a subsequent section and a third technique, the constant concentration integral technique, is presently under consideration by the authors.

\section{Tracer Injection Strategy}

Tracer gas techniques attempt to determine building airflow rates from the measured tracer concentration response of building airflow systems to carefully controlled injections of tracer gases. Inasmuch as the tracer injection strategy employed largely determines the capability and accuracy of a given tracer gas technique, these techniques can be classified by injection strategy. Presently, three injection strategies are commonly used;

1. decay: a suitable amount of tracer gas is injected into the building system to establish a uniform concentration within the system (i.e., an initial condition) and the ensuing concentration decay response is measured,

2. constant injection: tracer gas is injected at a constant rate and the resulting concentration response is measured (often with the expectation that practically steady state conditions exist), and

3. constant concentration: tracer gas is injected under instrumental control in an attempt to realize a constant and uniform tracer concentration throughout the building system.

\section{Mass Balance Relations}

The tracer gas concentration response to a given injection strategy may be described by mass balance equations that relate tracer concentrations to airflows. It is through these mass balance relations that one is able to estimate airflows from measured concentration data. These mass balance relations may be formulated in either an instantaneous form, which, for the multizone case, leads to systems of ordinary differential equations, or in an integral form that accounts for mass conservation over a given interval of time. Researchers have historically tended to favor the use of the instantaneous mass balance relations in the development of tracer gas techniques. A few researchers have, nevertheless, considered integral formulations for the reduction of concentration response data for these common injection strategies [Sinden 78 , Turiel 80, Penman 82, Walker 85, Waters 87]. Jensen [88] has demonstrated the use of 
integral mass balance relations in the reduction of data collected using an unusual "active" tracer injection strategy. To date, however, there has been no systematic attempt to reconsider the common tracer techniques from an integral point of view.

\section{Classification of Tracer Techniques}

As a unique tracer technique may be developed, in principal, for each injection strategy using either instantaneous or integral mass balance formulations, we may classify tracer gas techniques by both injection strategy and mass balance formulation. It is also useful to distinguish the application of each technique to either single or multi-zone building idealizations because of the significant mathematical differences of the corresponding mass balance relationships. The array of unique tracer techniques that may be considered for the three common injection strategies discussed above is tabulated below, in Table 1, along with indications of the capabilities that each technique may offer.

\begin{tabular}{|c|c|c|}
\hline \multirow{2}{*}{$\begin{array}{c}\text { Tracer } \\
\text { Injection Strategy }\end{array}$} & \multicolumn{2}{|c|}{ Mass Balance Formulation } \\
\hline & Instantaneous & Integral \\
\hline - Decay & $\begin{array}{l}\mathrm{SZ} \text { : yields infiltration } \\
\mathrm{MZ} \text { : yields all flows }\end{array}$ & (see Pulse Injection) \\
\hline $\begin{array}{l}\text { - Constant } \\
\text { Injection }\end{array}$ & $\begin{array}{l}\text { SZ: yields infiltration** } \\
\text { MZ: yields all flows** }\end{array}$ & $\begin{array}{l}\text { SZ: yields infiltration* } \\
\text { MZ: yields all flows* }\end{array}$ \\
\hline $\begin{array}{l}\text { - Constant } \\
\text { Concentration }\end{array}$ & $\begin{array}{l}\text { SZ: yields infiltration } \\
\text { MZ: yields only infiltration }\end{array}$ & $\begin{array}{l}\text { SZ: yields infiltration* } \\
\text { MZ: yields only infiltration* }\end{array}$ \\
\hline $\begin{array}{l}\text { - Pulse } \\
\text { Injection }\end{array}$ & (see Decay) & $\begin{array}{l}\text { SZ: yields infiltration } \\
\text { MZ: yields all flows }\end{array}$ \\
\hline
\end{tabular}

$\mathrm{SZ}=$ single-zone; $\mathrm{MZ}=$ multi-zone; *=presently under consideration; **=tends to underestimate

\section{Table 1 Classification of Tracer Techniques}

The tracer techniques based upon instantaneous formulations of the mass balance relations have been applied with varying degrees of success. The tracer techniques based upon the integral formulations have been largely ignored until recently and have yet to be studied thoroughly.

In particular, the constant injection technique may be applied to single and multi-zone situations to determine the details of infiltration, exfiltration, and zone-to-zone flows. The constant injection technique based upon an instantaneous formulation tends, however, to significantly underestimate infiltration airflows as commonly implemented (i.e., using average concentrations measured over relatively long time periods, as in the so-called Perfluorocarbon Tracer (PFT) method [Dietz 87]) [Bohac 87, Sherman 87]. It is believed that the integral formulation, to be discussed subsequently, will provide a means to mitigate this shortcoming.

The constant concentration technique has proven to be a reliable technique for single and multi-zone situations providing accurate determinations of outdoor airflow rates into the building zones [Sandberg 85], but does not provide any information regarding zone-to-zone airflows. When based upon an instantaneous formulation this technique requires careful control of the tracer injection rates that is realized using relatively sophisticated instrumental devices. It is believed that the integral formulation of the constant concentration technique, presently under consideration by the authors, will provide a means to implement this technique without the need 
for such careful, and therefore expensive, control.

The decay technique may be used to effectively determine infiltration airflows in buildings that behave as single-zone systems. It has also been applied to determine the details of infiltration, exfiltration, and zone-to-zone flows in buildings that behave as multi-zone systems. Several multi-zone decay techniques based upon instantaneous formulations have been considered including techniques based upon;

a) the measurement of both concentration responses and their first time derivatives [Sinden 78, Perera 82, Walker 85],

b) the consideration of the tracer gas response at times corresponding to a maximum concentration in one of the building zones (where the time derivative of concentration vanishes) [Dick 49], and

c) the intermediate determination of the system eigenmodes, assuming real-valued eigenvalues (i.e., inverse time constants) and nondegenerate eigenmodes (i.e., describing concentration response time histories as the sum of exponential decays) [Sinden 78], using, in some instances, Prony analysis [I'Anson 82, Irwin 85] to realize this determination.

Difficulties in measuring the first time derivative of concentration response have limited the success of the first approach [Sinden 78, Walker 85]. The authors simulated the application of the second approach for three and four zone cases, but it appeared that the approach was not well-conditioned enough to warrant further consideration. The third approach has yet to be applied to buildings that behave as more than four-zone systems and falters on the assumption of a nondegenerate system having real-valued eigenvalues; examples of systems that may demonstrate both degeneracy and imaginary eigenvalues have been presented [Sinden 78, Lawrance 87 , Waters 87]. Most multi-zone decay techniques rely on data collected very soon after the tracer gas injection. For this data to be reliable, the tracer gas injection must be wellmixed in each of the target zones. This is often a very difficult initial condition to achieve, and the accuracy of the results will be degraded by deviations from these assumed initial conditions.

\section{Pulse Injection Technique}

In this paper we shall consider the pulse injection technique, that was presented by Walker as the decay integral method [Walker 85] and further developed by Afonso and his colleagues [Afonso 86a, 86b, 86c]. This technique is based upon a tracer injection strategy of separate, short-duration, pulse injections of tracer into each zone of the building system and the application of integral mass balance equations to the reduction of the measured concentration response data.

Pulse excitations of flow systems are commonly used in the chemical process industry to determine dynamic characteristics of chemical process systems [Wen 75, Nauman 83, Westerterp 84] and Sandberg has described similar applications for buildings [Sandberg 83, 84]. The use of pulse excitation here is closer, however, to the tracer injection strategy suggested by Dick to extend decay methods to multi-zone problems [Dick 49]. In fact, the pulse injection technique may be considered to be an integral formulation of Dick's multi-zone decay technique. Although decay techniques employ pulse injections to establish initial concentrations, they have not used data collected during the time interval of the pulse to solve for airflows. In the pulse injection techniques we may choose to use.data collected during the time interval of the pulse. It is for this reason that we distinguish pulse injection techniques from traditional decay techniques.

It will be shown that the pulse injection technique may be applied to single and multi-zone situations to determine all airflows into, out of, and within the building system. The pulse and constant injection techniques are the only tracer gas techniques with this capability and, therefore, these two techniques will be compared. In addition, the pulse injection technique may be used to determine airflows in HVAC ducts. 
This paper will first consider the simplest case, the application of pulse injection techniques to the determination of flows in ducts, then move on to building applications, both single-zone building idealizations and multi-zone idealizations. Although there is only limited experience with the pulse injection techniques, we present discussion of experimental procedures and the results of applications of the techniques to the study of airflows in large buildings.

\section{DUCT PULSE TECHNIQUE}

The application of the pulse injection technique to the measurement of airflow in ducts provides a useful introduction to the pulse techniques in general. The underlying theory is especially straightforward and the utility of the technique appears to be great. Measuring airflow rates in ducts in building ventilation systems is difficult using traditional airflow rate measurement techniques (e.g. pitot tubes and hot-wire anemometers), due to insufficient lengths of straight ductwork for the establishment of fully-developed flow profiles. Constant injection tracer gas techniques have been used to measure these airflow rates [Lagus 1985], but they require one to wait for equilibrium and to measure very low tracer gas flow rates. The duct pulse technique is a simple and quick alternative for measuring these important quantities in even the most complex duct configurations.

\section{Theory}

Consider the duct segment illustrated below in Figure 1. Air flows into the duct from the left at a time-varying mass flow rate of $w(t)$. We inject a short duration tracer pulse at a rate $G(t)$ into the duct and measure the time variation of tracer concentration $C(t)$ at the exit.

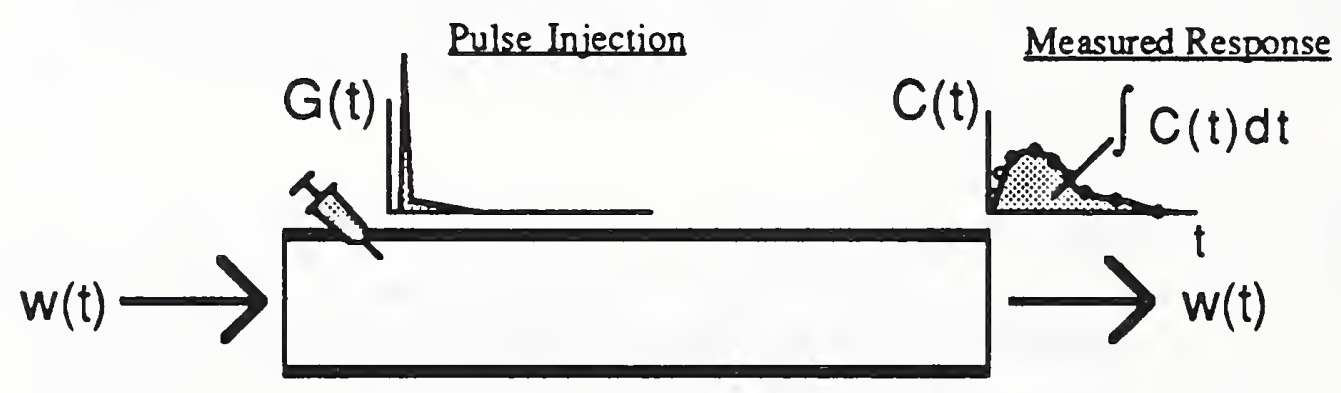

\section{Fig. 1 Duct Pulse Injection Technique}

Assuming that the tracer injection results in only trace concentrations and, therefore, does not contribute significantly to the air mass flow rate, then the exit air mass flow rate will equal $w(t)$. Furthermore, if the exit concentration measurement represents a flow-averaged concentration (e.g., the concentration is well-mixed across the section), then the mass flow rate of tracer exiting the duct will simply be equal to the product of the flow rate and the exit concentration, $w(t) C(t)$, where concentration is expressed in terms of the mass fraction of tracer relative to air. Recognizing that after some time interval, say $\left(t_{1}, t_{2}\right)$, all tracer will be purged from the duct, we may account for tracer mass conservation through the use of the following integral mass balance:

$$
\int_{t_{1}}^{t_{2}} w(t) C(t) d t=\int_{t_{1}}^{t_{2}} G(t) d t ; w(t) \geq 0
$$

which simply asserts that the tracer mass leaving the duct segment must equal the amount 
injected.

We may apply the integral mean value theorem to the expression on the left, as the concentration variation does not involve a sign change, and simplify to obtain the governing equation for the duct pulse injection tracer technique:

$w(\xi)=\left[\int_{t_{1}}^{t_{2}} C(t) d t\right]^{-1} \int_{t_{1}}^{t_{2}} G(t) d t \quad ; t_{1} \leq \xi \leq t_{2}$

In words, we may determine the air mass flow rate that occurred at some time, $\xi$, during the time interval $\left(t_{1}, t_{2}\right)$ by simply computing the ratio of the mass of tracer injected to the integral of the concentration response downstream from the tracer. Clearly if the air mass flow rate is constant, the determination will yield this constant value. If the air mass flow rate changes very little during the interval, then $w(\xi)$ should be a good estimate of the average flow rate during that interval.

\section{Experimental Procedures}

In applying the duct pulse technique to an actual length of duct there are several practical considerations. The most important issues are knowing the mass of tracer that is injected and obtaining an accurate determination of the concentration integral. Since one only requires the integral of the $G(t)$, the actual injection profile is irrelevant. It is only important to know the injection mass. This mass can be measured before or during the injection, but it is crucial that all of the tracer gas is injected into the duct.

The duct pulse measurement technique requires only the determination of the integral of the concentration at the downstream measurement point, not the concentration time history. The determination of this integral relies on more than just accurate measurement of tracer gas concentrations. The concentration in the duct, at the point of measurement, must be varying only along the length of the duct, not across the duct cross-section. Otherwise, the integral must be based on a cross-sectional average concentration. A multi-point injection across a duct cross-section, as opposed to a single point injection, can assist in achieving a uniform concentration across the cross-section at the concentration measurement point.

Because the concentration response will be relatively short-lived, it will be difficult to determine the concentration integral from numerical integration of the concentration data unless one's concentration measuring equipment has a high sampling frequency and covers a wide range of measurable concentrations. Therefore, it is advantageous to determine the concentration integral through the measurement of the average tracer gas concentration at the measurement point. This average concentration can be determined by filling an appropriate air sample container, beginning well before the pulse is injected and continuing until the pulse is completely purged from the duct. The concentration integral simply equals the average concentration multiplied by the length of the time over which the sample container is filled.

In applying this technique to a particular system there will always be some initial uncertainty in the amount of tracer gas that should be injected into the ductwork. The primary requirement is that the average concentration in the air sample container is in the accurately measurable range of one's tracer gas concentration measurement equipment. Meeting this requirement depends on choosing an appropriate combination of injection mass and concentration averaging period. In general, there will be some "trial-and-error" in determining these quantities. Since each measurement requires only a few minutes, it is not difficult to find appropriate values for these quantities. In addition, because the time required to make a measurement is so short, an airflow measurement can be repeated several times, thereby obtaining an estimate of the repeatability of the tests. 


\section{Measured Results}

Some preliminary applications of the duct pulse technique have been conducted in the HVAC system of a mechanically ventilated office building. A comparison between the results of these duct pulse measurements and the airflow rates measured by a hot-wire traverse is shown in Figure 2. These results lie in three distinct regions, depending on the type of duct that was studied. In the ducts corresponding to the two lower airflow rates, a premeasured amount of tracer gas was injected by hand. In the measurements corresponding to the higher airflow rates, the tracer gas was injected through a calibrated flow meter. In all of these tests, the concentration integral was based on an average concentration determined by filling an air sample bag with a battery operated pump over a period beginning at least one minute before the injection and lasting several minutes after the injection was complete. In these tests, the injection mass and sampling period were varied to examine the sensitivity of the results to these variables, and the measurements were repeatable to within about $5 \%$. The agreement between the duct pulse results and the results of the hot-wire traverses are encouraging given the uncertainties in the hot-wire readings and additional errors due to the unknown flow profile at the duct walls and uncertainties in the inside area of the duct. A detailed, laboratory study of the duct pulse technique is still necessary to provide a rigorous validation of the technique.

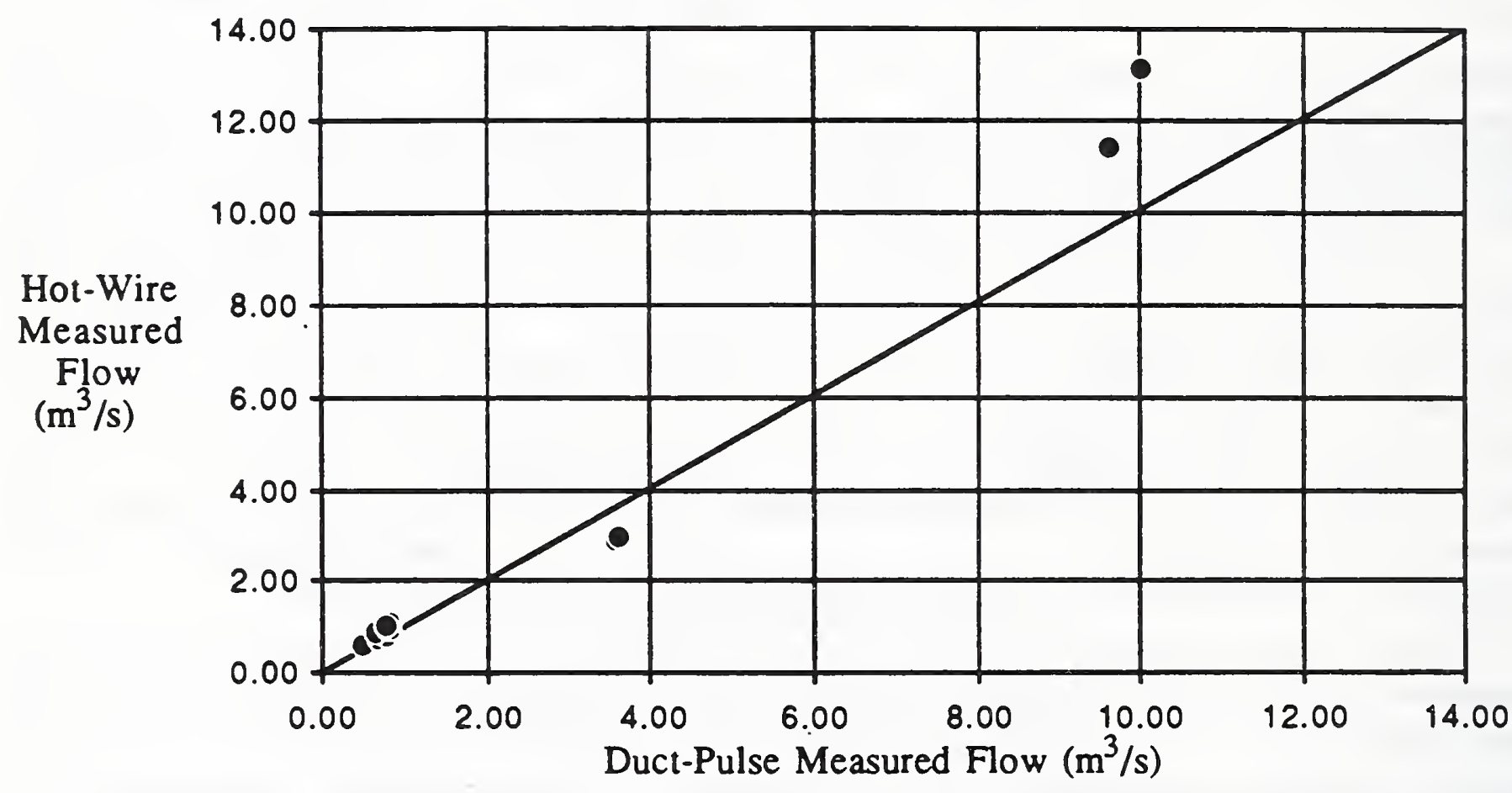

Fig, 2 Comparison of Duct-Pulse and Hot-Wire Measurements

\section{BUILDING PULSE TECHNIQUES}

Building and chemical process flow systems may be thought of as well or partially mixed zones connected by flow paths (i.e., supply, return, and exhaust ducts in buildings; inlet and outlet pipes in chemical process systems). One may, then, consider subjecting a flow system to a) pulse excitations of the flow paths, b) pulse excitations of the zones, or c) a combination of a) and b). The duct pulse technique, based upon a flow path excitation, is possible because the inlet and outlet flow paths of a duct are (presumably) known with certaintyl. The flow paths

1 Note: if the duct pulse technique was applied, as described, to a long leaky duct not all tracer mass transport would be accounted for and, therefore, errors would result However, in the case of a leaky duct, one could actually quantify the amount of duct leakage by employing a series of pulse injections and/or concentration response measurements along the length of the duct. 
in chemical process flow systems are also known with certainty and, as a result, flow path excitation is commonly used for these systems. For buildings, on the other hand, the analyst will seldom have complete knowledge of all flow paths (e.g., infiltration, exfiltration, and zoneto-zone) and, therefore, to determine both the general topology and magnitude of airflows in the building airflow system the analyst will have to employ pulse excitation of the zones rather than the flow paths. As the analyst becomes better acquainted with a given building flow system then it may be possible to use a combination of flow path and zone pulse excitations.

Here, we formulate the theory relating to pulse excitation of ideally well-mixed zones in building systems, considering, first, the single-zone idealization then the general multi-zone idealization of building airflow systems. The theoretical development parallels that presented for ducts but now we must include the possibility of accumulation of tracer within zones.

\section{Single Zone Pulse Technique}

\section{Theory}

Consider the single-zone idealization illustrated below in Figure 3. Airflows into the zone at a mass flow rate of $w(t)$ and is assumed to be instantaneously and uniformly mixed within the zone. A short duration tracer pulse is injected into the zone and the zone concentration response to the pulse, $C(t)$, is measured.

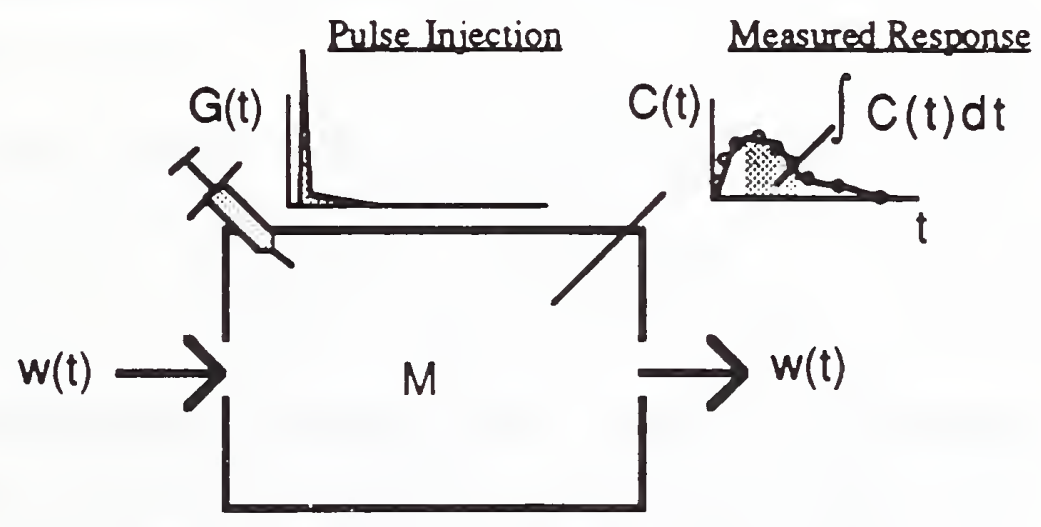

Fig. 3 Single Zone Pulse Injection Technique

Again we assume that the tracer injection mass is small enough such that the exit air mass flow rate is practically equal to the inlet rate. We may write an instantaneous mass balance relation for this single-zone idealization, with $M$ equal to the mass of air within the zone, as:

$w(t) C(t)+M \frac{d C(t)}{d t}=G(t) ; w(t) \geq 0$

where we have assumed the concentration of tracer outside to be zero. In words, at any instant in time the mass flow rate of tracer out of the zone, $w(t) C(t)$, plus the accumulation of tracer within the zone, $M d C / d t$, is equal to the rate of generation (i.e., injection) of the tracer, $G(t)$.

We may also demand that tracer mass be conserved over any arbitrary time interval, say $\left(t_{1}, t_{2}\right)$, by directly integrating equation (3) over the time interval to obtain;

$\int_{t_{1}}^{t_{2}} w(t) C(t) d t+M \Delta C=\int_{t_{1}}^{t_{2}} G(t) d t$

where $\Delta C \equiv C\left(t_{2}\right)-C\left(t_{1}\right)$. Again we apply the integral mean value theorem to the first integral and simplify to obtain the governing equation for the single-zone pulse injection tracer 
technique:

$w(\xi)=\left[\int_{t_{1}}^{t_{2}} C(t) d t\right]^{-1}\left[\int_{t_{1}}^{t_{2}} G(t) d t-M \Delta C\right] ; t_{1} \leq \xi \leq t_{2}$

For the single-zone system, then, it is seen that we may determine the air mass flow rate that occurred at some time, $\xi$, during the time interval $\left(t_{1}, t_{2}\right)$ by simply computing the ratio of the mass of tracer injected, corrected by the amount of tracer accumulated $-M \Delta C$, to the integral of the concentration response downstream from the tracer. Again, if the air mass flow rate is constant the determination will yield this constant value. If the air mass flow rate changes very little during the time interval, then $w(\xi)$ should be a good estimate of the average flow rate during that interval.

By explicitly accounting for the accumulation, $M \Delta C$, we are able to consider any time interval we desire; we do not require complete purging of the tracer as before. This widens the possible experimental options as discussed below. We may consider a time interval sufficiently long to allow complete purging, or short time intervals that in the limit approach an instant in time, which would in theory provide instantaneous determinations of airflow rates.

\section{Experimental Procedures}

The use of the single zone pulse technique to measure the air exchange rate of a zone is based on the assumption that the zone is well-mixed (i.e. the tracer gas concentration in the zone can be characterized by a single value). To increase the appropriateness of this assumption, it is important to release the tracer gas as uniformly as possible throughout the space being tested. As in the duct pulse technique, it is important to know the mass of tracer gas released, not the injection time history. The gas can be released directly into the space itself using a multi-point injection scheme or by moving the injection outlet through the space during the release. Such a "within-the-space" injection can be difficult in a large or complex zone, in which case the gas can instead be injected into the supply duct serving that zone, if one exists. Using the supply air distribution system to inject the tracer can provide a uniform dispersal of the tracer gas, but one must be sure that all of the gas gets to the space (i.e., the supply ductwork does not leak). In many systems this assumption can not be justified, but as discussed below, one can still use the supply air system for injection by not including the injection period in the concentration integral.

As with the duct pulse technique, one only needs the integral of the tracer gas concentration in the zone. This can be determined with real-time sampling or with an average air sample taken during the integration period. Although the use of this technique employs the assumption that the concentration is uniform throughout the zone, the tracer gas concentration should be sampled at several locations in order to verify this assumption. The time interval over which the integral is determined need not include the tracer gas injection, nor need it last until the tracer gas concentration goes to zero. If the integral includes the tracer gas injection, then the injection mass must be known precisely and be well dispersed throughout the test space. If the injection period is not included in the integral then the injection mass need not be known, though it needs to be controlled such that the concentration within the zone is in the measurable range of the tracer gas detector. The integral of $G(t)$ in equation (5) will equal zero, but the value of $M \Delta C$ will be large due to the significant tracer gas concentration at $t=t_{1}$.

The duration of the integration period involves a trade off between one's ability to accurately measure low concentrations and one's knowledge of the zone mass $M$. During the tail of the concentration response, the tracer concentrations will be very low and may be difficult to measure accurately. One can avoid this source of error in the integral by choosing $t_{2}$ to be a 
time when the concentrations are still within a range that can be accurately determined. In this case, the term $M \Delta C$ may be significant, and if it is, an accurate knowledge of $M$ will be important. The importance of knowing $M$ accurately depends on the relative magnitudes of the integral of $G(t)$ and of $M \Delta C$.

If the concentration response to the pulse is very short lived, corresponding to a high air exchange rate, then one should employ an average concentration to determine the integral. This averaging should begin well before the tracer gas injection and continue until the concentration within the zone has decreased to essentially zero. This approach enables the determination of the air exchange rate of a single zone based on a single air sample of the average concentration, but one must be certain that the tracer gas concentration is zero at $t=t_{2}$. If it is not, then an additional air sample must be taken at this time to compute the $M \Delta C$ term. This approach enables the low-cost determination of single zone air exchange rates with on-site air sampling and off-site tracer gas concentration analysis

\section{Measured Results}

Afonso et. al. [Afonso 86, 87] report the results of single zone pulse tests conducted in a laboratory test facility in which the airflow rate into the zone was measured with nozzles. Four tests were conducted at four different supply airflow rates into the zone. The measurements of the space air exchange rate were generally repeatable within $3 \%$, and the agreement with the supply airflow rates measured with the nozzle ranged from 10 to $17 \%$. The values calculated from the pulse tests were always less than the measured airflow rates, probably due to air leakage from the supply ducts. In these experiments, the room mass $M$ was treated as an unknown and was solved for by evaluating equation (5) both before and after the tracer gas injection.

\section{Comparison of Single-Zone Pulse and Constant Injection Techniques}

The pulse and constant injection techniques can both be used to determine the air exchange rate of a single well-mixed zone. A pulse measurement will generally last only a few building time constants (inverse of the air exchange rate), while the constant injection technique has been applied for periods from several days to several weeks. In both cases, the effect of variations in the air exchange rate during the measurement period will affect the results of the measurements. The discussion below examines these effects of flow variation in comparing the pulse and constant injection techniques.

\section{Theory: Constant Injection Technique}

Consider, now, for purposes of comparison, a well-mixed zone subjected to a constant injection of tracer as illustrated below in Figure 4.

We may again apply the instantaneous and integral mass balance relations presented above, equations (3) and (5), with $G(t)=G_{0}$. If the airflow remains steady then eventually a steady state response will be achieved:

$C(t \rightarrow \infty)=$ constant $; \frac{d C(t \rightarrow \infty)}{d t}=0 ; w(t)=$ steady

and by the instantaneous mass balance, equation (3), we obtain:

$w(t)=\frac{G_{0}}{C(t \rightarrow \infty)} ; w(t)=$ steady 
This expression is the basis of the constant injection technique; flow is estimated by the quotient of the constant injection rate divided by the steady state concentration.

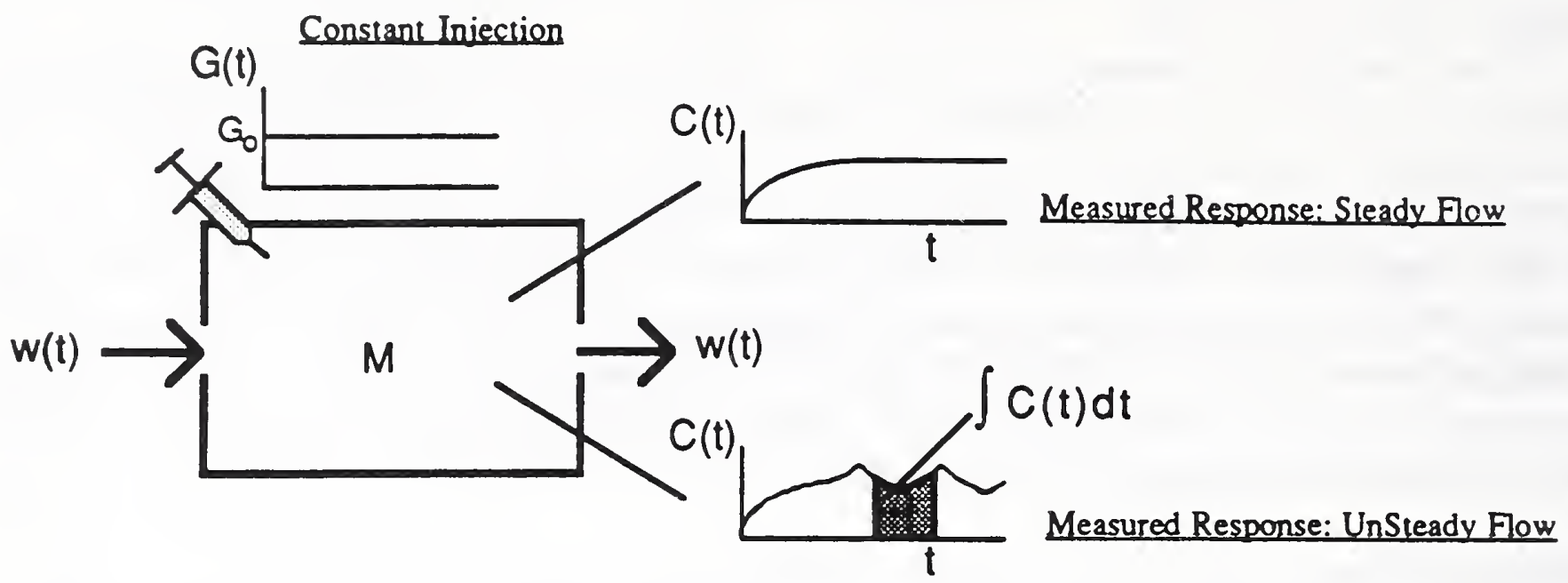

\section{Fig. 4 Single-Zone Constant Injection Technique}

In many practical situations, however, the flow will seldom be constant long enough to achieve a steady state response, therefore, it has become common practice to use average concentration measurements, in place of the steady state value, in equation (7) to estimate airflows. The time intervals over which these average measurements are made range, typically, from a single day to several weeks. Early on it had been hoped that the use of average concentration measurements in equation (7) would provide acceptable approximations of the mean airflow occurring over the averaging time interval, but more recently it has been shown that this approximation may significantly underestimate the mean flow [Bohac 87, Sherman 87]. The question remains, then, if this approximation does not provide an estimate of the mean flow, what estimate does it provide?

From the integral mass balance relation, equation (5), with $G(t)=G_{0}$, we may obtain the following expression:

$w(\xi)=\frac{G_{0}-M(\Delta C / \Delta t)}{\bar{C}} ; \Delta t \equiv t_{2}-t_{1} ; t_{1} \leq \xi \leq t_{2}$

where $\bar{C}$ is the mean concentration measured over the interval $\left(t_{1}, t_{2}\right)$. Equation (8) defines the basis of an alternate constant injection tracer technique, discussed below, that we designate as the integral constant injection technique.

For averaging intervals on the order of days to weeks $M(\Delta C / \Delta t)$ will generally be negligibly small and thus we may presume that:

$w(\xi)=\frac{G_{0}}{\bar{C}} ; \Delta t \equiv t_{2}-t_{1} ; t_{1} \leq \xi \leq t_{2}$

Thus, it is seen that the approximation using average concentration measurements yields an estimate of flow that occurred at some time, $\xi$, during the averaging interval which, in general, will not equal the mean value. Ironically the constant injection technique, as practically applied using long-term averages, is actually an "integral technique" rather than an "instantaneous technique" as originally presented. 


\section{Harmonic Flow Variation}

By employing the integral mean value theorem we have derived governing equations for both the pulse injection and constant injection technique that account for flow variation. The results, equations (5), (8) and (9), leave, however, much to be desired from a practical point of view. Although they provide a rigorous estimate of flow that occurred at some time, $\xi$, during the integration time interval, that time is unknown and the results provide no information regarding how the flow estimate relates to the actual flow variation.

We may gain some insight into the affect of flow variation about a mean value on both the pulse injection and constant injection techniques by considering the special case of harmonic flow variation:

$w(t)=\bar{w}(1+\alpha \cos (2 \pi t / T))$

where $\bar{w}$ is the mean flow, $\alpha$ is the amplitude of flow variation, and $T$ is the period of the variation. Substituting equation (10) into equation (3) and solving we obtain expressions for the concentration time histories for both injection strategies.

Pulse Injection Response: For an impulse injection of tracer (i.e., a very short duration, relative to the system time constant, pulse) of amount I:

$G(t)=I \delta(t) ; \int_{0}^{t} G(t) d t=\int_{0}^{t} I \delta(t) d t=1 ; \delta(t=0)=1 ; \delta(t \neq 0)=0$

we obtain:

$C(t)=\left(\frac{1}{M}\right) \exp \left(-\frac{t}{\tau}-\left(\frac{\alpha T}{2 \pi \tau}\right) \sin \left(\frac{2 \pi \tau}{T} \frac{t}{\tau}\right)\right)$

where $\tau$ is the system time constant under the mean flow conditions, $\tau \equiv(M / \bar{W})$. This equation describes a decay response that includes an oscillatory component as illustrated in Figures 5 and 6 . The difference between the responses in Figures 5 and 6 is that the former corresponds to the flow rate assuming its maximum value at $t=0$ (i.e., $\alpha=1.0$ ), while Figure 6 corresponds to the minimum airflow rate at $t=0$ (i.e., $\alpha=-1.0$ ).

Constant Injection Response: For constant injection, $G(t)=G_{0}$, we obtain:

$C(t)=\left(\frac{G_{0}}{\bar{W}}\right) \frac{\int_{0}^{(t / \tau)} \exp \left(\frac{t}{\tau}+\left(\frac{\alpha T}{2 \pi \tau}\right) \sin \left(\frac{2 \pi \tau}{T} \frac{t}{\tau}\right)\right) d\left(\frac{t}{\tau}\right)}{\exp \left(\frac{1}{\tau}+\left(\frac{\alpha T}{2 \pi \tau}\right) \sin \left(\frac{2 \pi \tau}{T} \frac{t}{\tau}\right)\right)}$

This equation describes a build-up response having an oscillatory component as illustrated in Figure 7. 


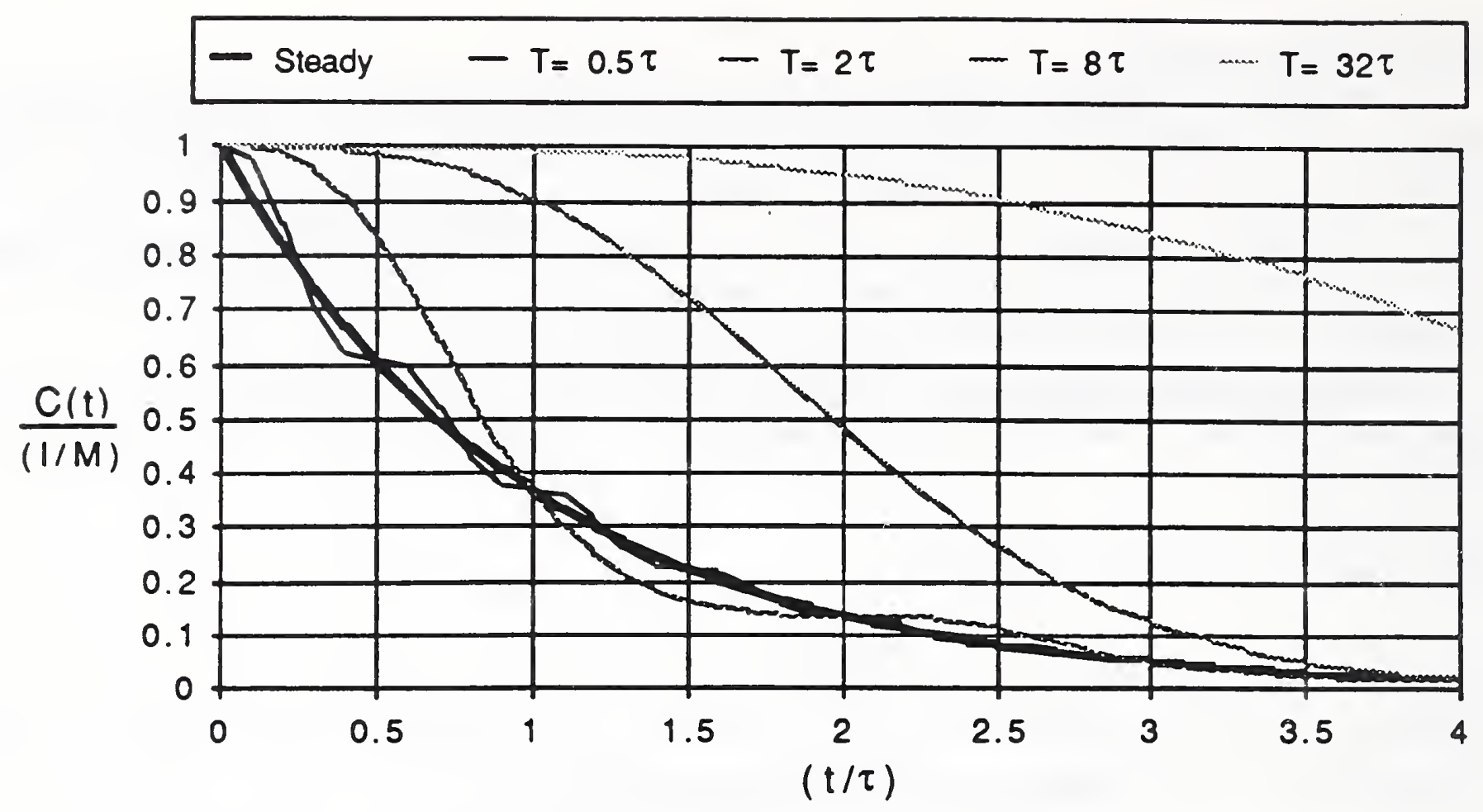

Fig. 5 Pulse Injection Response for $\alpha=1.0$

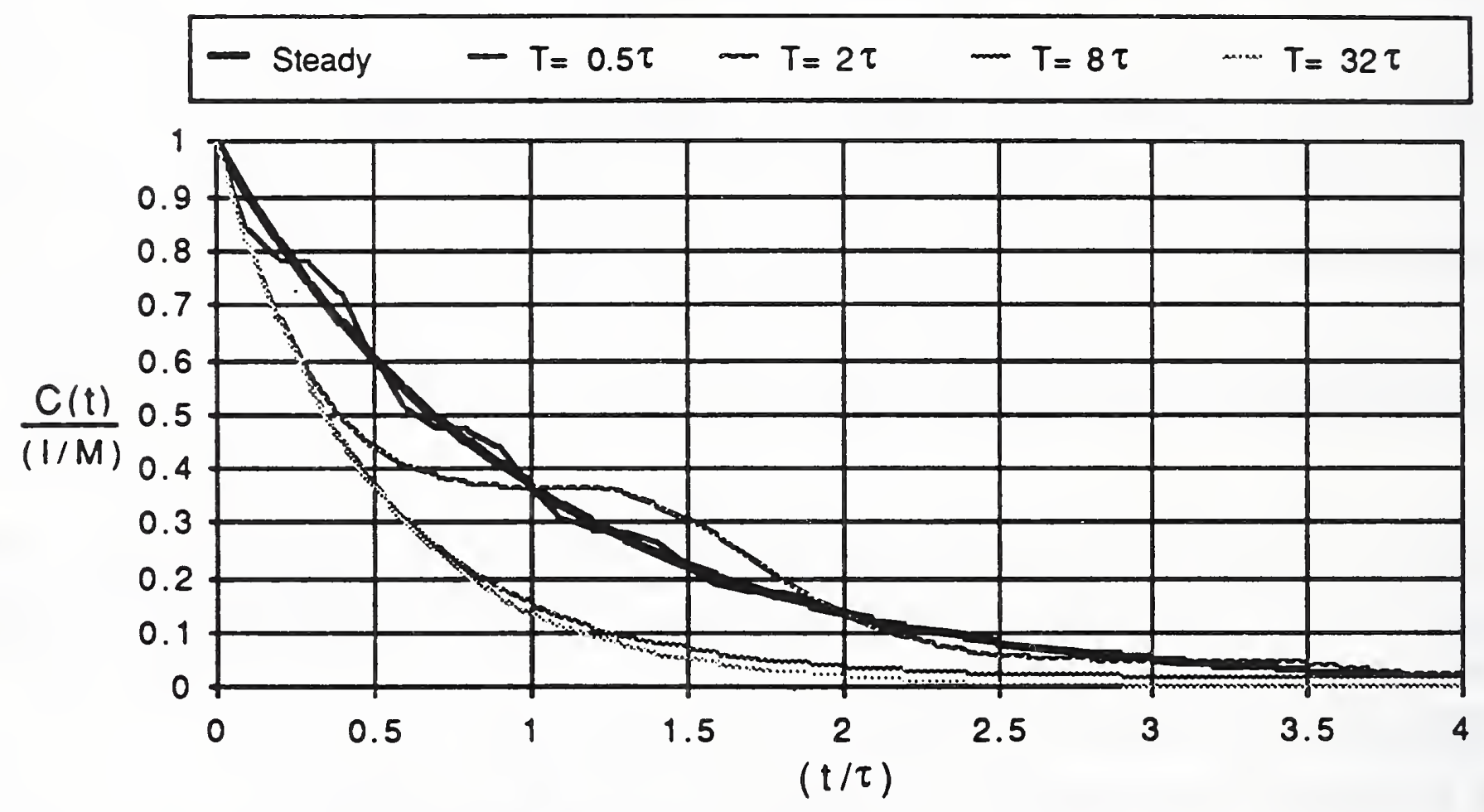

Fig. 6 Pulse Injection Response for $\alpha=-1.0$ 


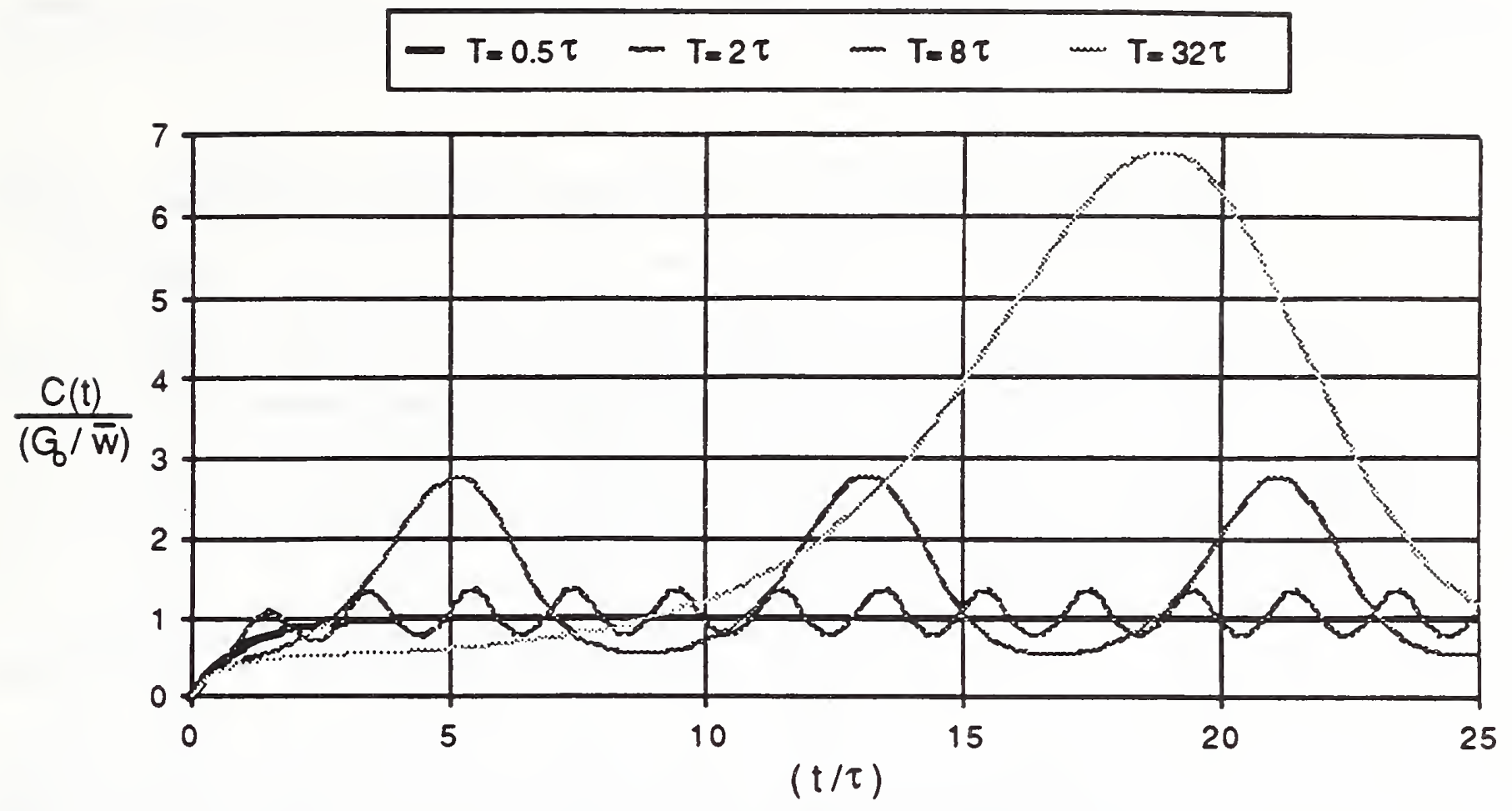

Fig. 7 Constant Injection Response for $\alpha=1.0$

These figures clearly reveal the importance of the period of variation of flow. Specifically, when the period of variation of flow is small relative to the mean flow time constant, $\tau$, then both the pulse injection response and the constant injection response closely approximate the mean flow response. We conclude then:

1. For flow variations having periods of variation small relative to the system mean-flow time constant, both pulse injection and constant injection techniques will provide accurate estimates of the mean flow rate regardless of the amplitude of flow variation.

At the other extreme, it is also clear that flow variations having periods of variation much greater than the mean flow time constant may greatly distort the response relative to the mean flow response. For these long period variations, we may conclude:

2. If integration time intervals are selected to be small relative to the period of flow variation then both the pulse injection technique and an integral constant injection technique defined by equation (8) will provide accurate estimates of nearinstantaneous flow rates.

3. If integration time intervals are selected nearly equal to the period of variation (e.g., 0.2 $T \leq \Delta \mathrm{t} \leq 5 T$ ) then the pulse injection and constant injection techniques may under-or over-estimate the mean flow rate depending upon the actual timing of the integration interval relative to the flow variation.

4. If integration time intervals are selected to be very large, or a multiple of the period of flow variation, then for constant injection the average concentration will overestimate the mean flow steady state concentration and, as a result, the constant injection technique will underestimate this mean flow. (For the pulse injection technique, integration time intervals are practically limited to 2 to 4 times the mean flow time constant and thus this case need not be considered.)

Conclusion 4 may be evaluated numerically by substituting equation (13) into equation (8) and integrating over one period of variation after steady periodic conditions have been realized. The results of this exercise are plotted below in Figure 8. From these results it is seen that the flow determined by constant injection and long-term average concentrations, $w(\xi)$, may underestimate the actual mean flow, $\bar{w}$, by 10 to $30 \%$ for moderate amplitude flow variations (i.e., for $\alpha$ in the range of 0.5 to 0.7 ) when the period of flow variation is on the order of ten or 
more times the mean flow time constant. Bohac [88] and Sherman [87] have both reported underestimation errors of this magnitude.

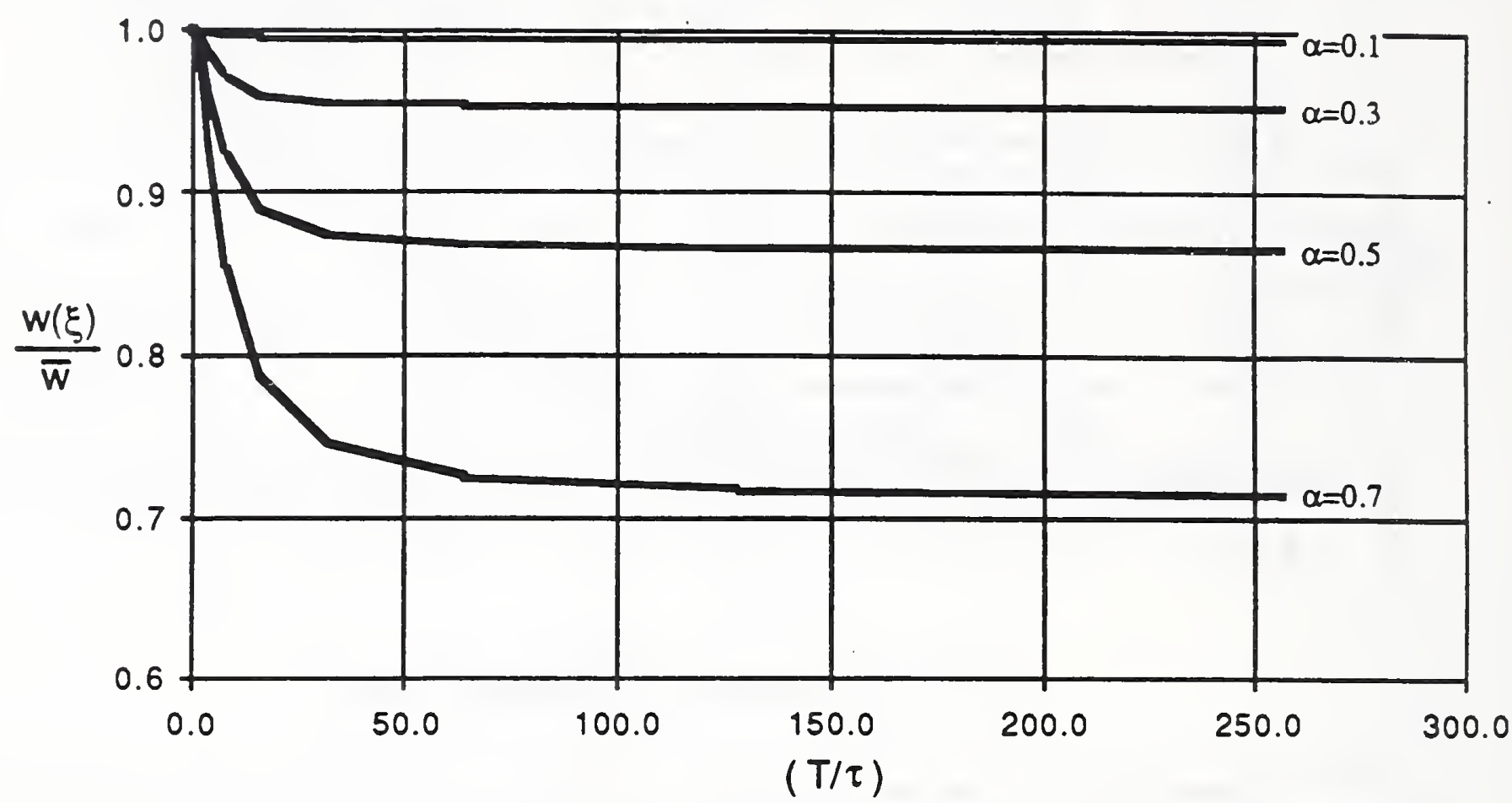

Fig. 8 Ratio of Constant Injection Estimated Flow Rate to Mean Flow Rate for Long Averaging Time Intervals

Given the importance of long-period flow variations, it is natural to ask if one should expect to encounter such long-period flow variations in the field. Infiltration time constants for buildings range, typically from 0.5 to 5 hours (i.e., infiltration rates of 0.20 to 2.0 air changes per hour may be considered typical), thus, from a practical point of view we should be particularly concerned with periods of flow variation exceeding from 5 to 50 hours. Flow variations driven by occupant intervention and HVAC system operation are likely to introduce a diurnal, 24 hour, component (e.g., night set-back of heating and cooling systems and daily airings of occupied spaces) that should be expected to be important in buildings having higher infiltration rates. Flow variations driven by wind and ambient temperature variations may be expected to reflect the spectral content of the wind and thermal environment both of which reveal significant variations in the semi-diumal, 12 hour, to several-day time periods (i.e., periods associated with weather variation) and, therefore, may be expected to important for all buildings. Therefore, long-period flow variations can be expected to be commonplace in the field and will introduce errors in the airflow rates determined with the constant injection technique.

\section{Multi-Zone Theory}

The development of the theory for multi-zone building idealizations follows that presented above for single-zone idealizations in that we shall consider, first, instantaneous mass balance equations and from them derive integral mass balance relations using the integral mean value theorem. Now, however, we shall have to consider systems of equations and, consequently, the solution for airflows will involve matrix, rather than scalar, algebraic operations. As a result, the issues of singularity and conditioning of the resulting equations will become a central concern and will, largely, determine the success or failure of any proposed multi-zone tracer technique.

We begin by stating that contaminant dispersal in a multi-zone idealization of a building airflow system may be described by the following instantaneous mass balance equations (see 
[Axley $87,88 \mathrm{a}, 88 \mathrm{~b}$ ] for complete details):

$[W]\{C\}+[M] \frac{d\{C\}}{d t}=\{G\}$

where;

[W] is the system mass transport matrix,

\{C is a vector of nodal concentrations (i.e., concentrations at discrete spacial locations in the building airflow system), which, for our purposes corresponds to a vector of zonal concentrations,

[M] is the system mass matrix, which, for our purposes is a diagonal matrix with entries equal to the mass of the volume of air contained in each zone,

\{G\} is the system generation vector, which, for our purposes is a vector of zonal tracer mass generation rates.

The system transport matrix is, in general, assembled from expressions defining mass transport due to both flow and nonflow transport processes (e.g., airflow rates and chemical and physical rate constants). Consequently, one may devise tracer gas techniques to determine the elements of this matrix from measured concentration data, and thereby determine the characteristics of both flow and nonflow transport processes that define this matrix. Our purpose is somewhat more limited; we seek to determine the flow characteristics of a multizone building airflow system using tracers that are affected only by flow transport processes and leave the determination of the characteristics of nonflow transport processes to future study.

To this end we shall consider the determination of airflows for a multi-zone building idealization consisting of $\mathrm{n}$ well-mixed building zones and a single well-mixed exterior (i.e., outdoor) "zone," with single flow paths linking each of these zone to all others. Furthermore, we shall assume that airflow from zone-to-zone is practically instantaneous. A three-zone example of such an idealization is illustrated below in Figure 9.

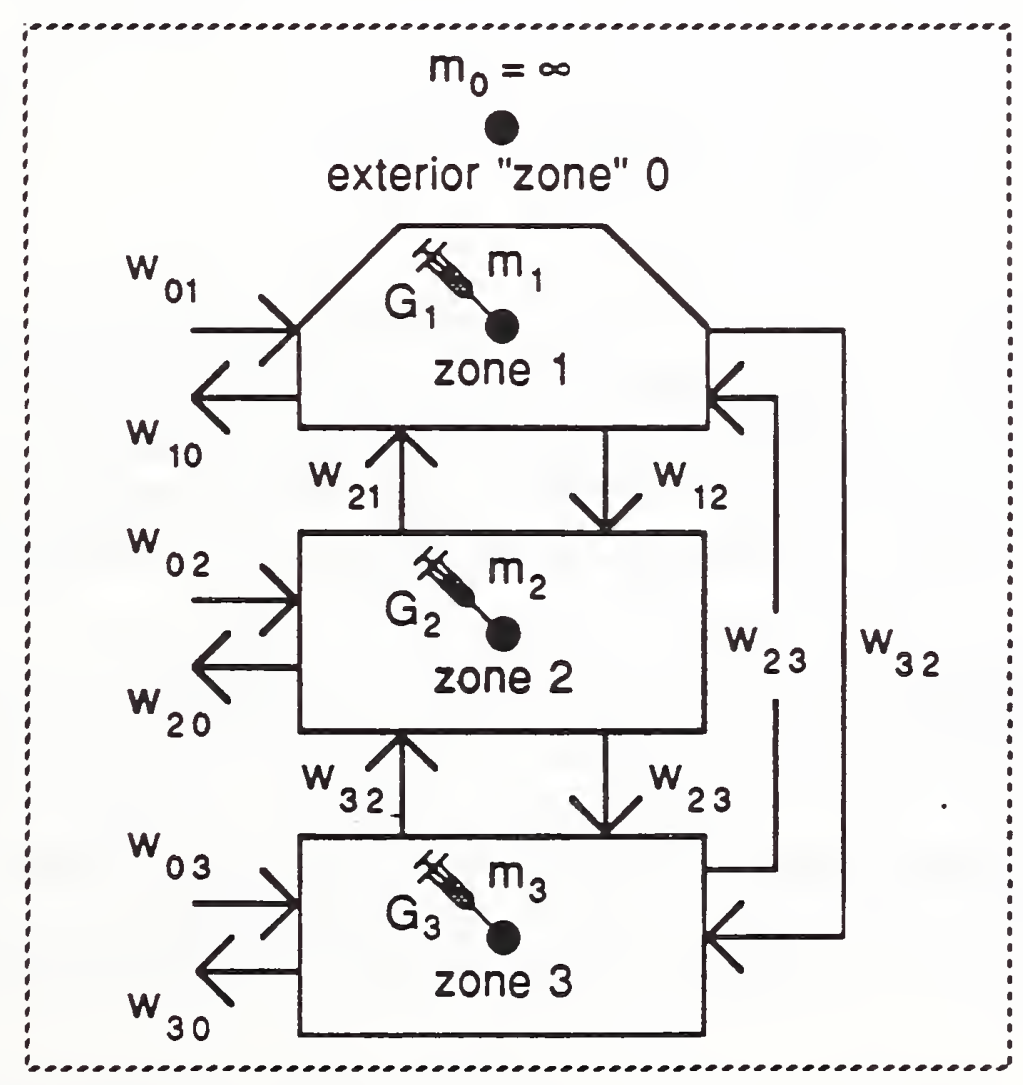

Fig. 9 A Three-Building-Zone Idealization 
It will be convenient to identify the exterior zone as zone "0" and number the building zones from 1 to $\mathrm{n}$, so that the elements of the concentration vector, $\{\mathrm{C}\}$, the system mass matrix, $[\mathrm{M}]$, and the system generation vector, $\{\mathrm{G}\}$, are:

$\{C\}^{\top}=\left\{C_{0}, C_{1}, C_{2}, \ldots C_{n}\right\}^{\top}$

$[M]=\operatorname{diag}\left\{m_{0}, m_{1}, m_{2}, \ldots m_{n}\right\}$

$\left\{G^{\top}=\left\{G_{0}, G_{1}, G_{2}, \ldots G_{n}\right\}^{\top}\right.$

where $C_{i}, m_{i}$, and $G_{i}$ are, respectively, the concentration of tracer in zone $i$ (expressed in terms of mass fraction; mass tracer/mass air), the mass of the volume of air in zone $i$, and the mass generation rate of tracer in zone $i$. (The mass of air in the exterior zone " 0 " shall be considered infinite.)

Designating the mass flow rate of air from zone $\mathrm{i}$ to zone $\mathrm{j}$ by $\mathrm{w}_{\mathrm{ij}}$, we may directly assemble the system mass transport matrix to obtain:

$$
[W] \equiv\left[\begin{array}{ccccc}
w_{00} & w_{01} & \ldots & w_{0 n} \\
w_{10} & w_{11} & \ldots & w_{1 n} \\
\ldots & \ldots & \ldots & \ldots \\
w_{n 0} & w_{n 1} & \cdots & w_{n n}
\end{array}\right]=\left[\begin{array}{cccc}
\left(\sum_{j=0 ; \neq 0}^{n} w_{0 j}\right) & -w_{10} & \cdots & -w_{n 0} \\
-w_{01} & \left(\sum_{j=0 ; \neq 1}^{n} w_{1 j}\right) & \cdots & -w_{n 1} \\
\ldots & \ldots & \ldots & \ldots \\
-w_{0 n} & -w_{1 n} & \cdots & \left(\sum_{j=0 ; \neq n}^{n} w_{n j}\right)
\end{array}\right]
$$

where we admit only positive values for $\mathrm{w}_{\mathrm{ij}}$. It should be noted that the diagonal terms are equal to total air mass flow out of each zone.

The central objective of multi-zone tracer techniques is to determine the elements of the mass transport matrix, [W], and thereby determine the airflows, $W_{i j}$, in equation (18). With this objective in mind we may transpose and rewrite equation (14) in the following form:

$\{C\}^{\top}[\mathbf{W}]^{\top}=\left\{\{\mathbf{G}\}-[\mathbf{M}] \frac{d\{C\}}{d t}\right\}^{\top}$

which, when expanded, has the form: 
$\left\{C_{0}, C_{1}, \ldots C_{n}\right\}\left[\begin{array}{cccc}W_{00} & W_{10} & \ldots & W_{n 0} \\ W_{01} & W_{11} & \ldots & W_{n 1} \\ \ldots & \ldots & \ldots & \ldots \\ W_{0 n} & W_{1 n} & \ldots & W_{n n}\end{array}\right]=\left\{\left(G_{0}-m_{0} \frac{d C_{0}}{d t}\right),\left(G_{1}-m_{1} \frac{d C_{1}}{d t}\right), \ldots\left(G_{n}-m_{n} \frac{d C_{n}}{d t}\right)\right\}$

From the point of view of tracer analysis the $C_{j}$ 's, $G_{j}$ 's, and $d C_{j} / d t$ 's may be considered to be quantities that are measured at some instant in time with the $G_{j}$ 's defining the tracer injection at that time and the $C_{i}$ 's and $d C_{i} / d t^{\prime}$ s the corresponding concentration response. Together we shall designate these quantities, determined at some instant in time, as an instantaneous data set. To distinguish data set $i$ from all others we shall use the superscript $i$ as follows:

\section{Instantaneous Data Set i}

$$
\left\{C_{0}^{i}, C_{1}^{i}, \ldots C_{n}^{i}\right\},\left\{\frac{d C_{0}^{i}}{d t}, \frac{d C_{1}^{i}}{d t}, \ldots \frac{d C_{n}^{i}}{d t}\right\},\left\{G_{0}^{i}, G_{1}^{i}, \ldots G_{n}^{i}\right\}
$$

From the form of equation (19) it is clear that we shall need $(n+1)$ data sets to define a determined set of equations (i.e., to have sufficient equations to determine the elements of the [W] matrix):

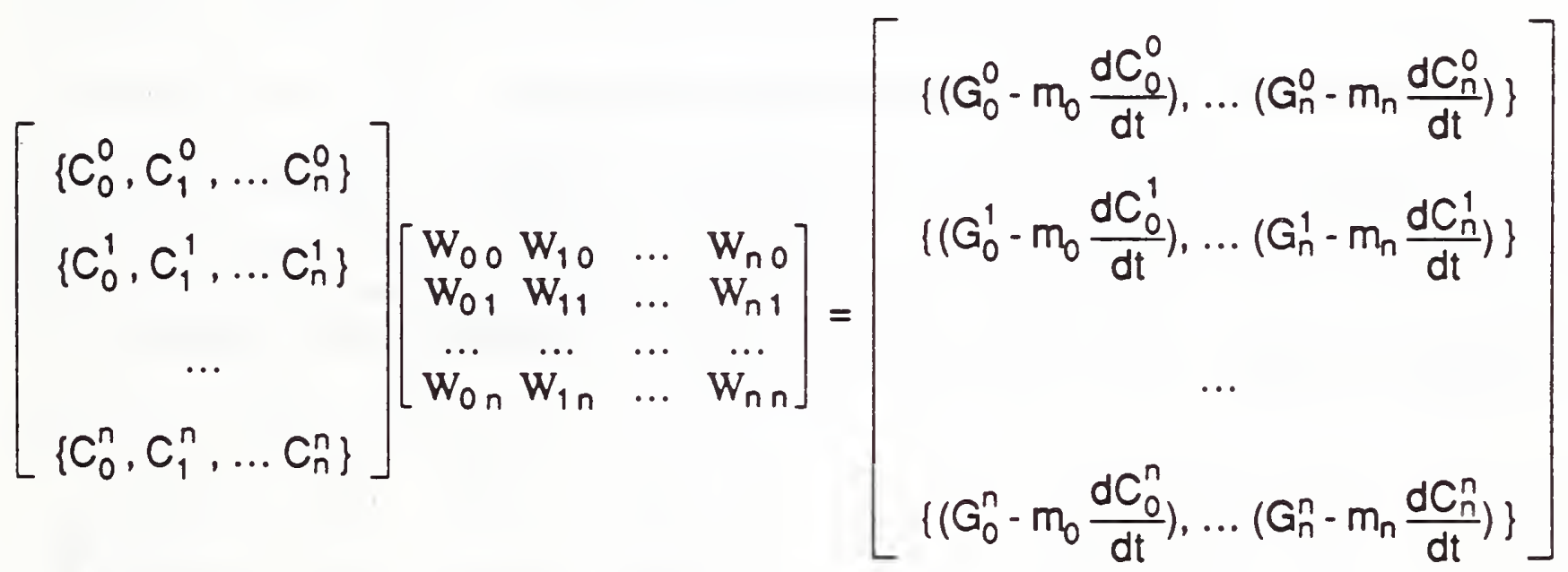

To simplify notation we shall represent equation (20a) as:

$[C][W]^{\top}=[T]$

The (instantaneous) concentration matrix, [C], would be formed from measured tracer concentration data; the (instantaneous) tracer rate matrix, $[T]$, would be formed from the known tracer injection rates corrected by the "mdC/dt" accumulation rate term. This set of equations defines the instantaneous inverse (contaminant dispersal) problem.

Following the same procedure used above in the single-zone theory we may also formulate the integral inverse (contaminant dispersal) problem. We begin by integrating equation (19) over an arbitrary time interval, $\left(t_{1}, t_{2}\right)$, and apply the integral mean value theorem to obtain:

$\left\{\int C_{0}, \int C_{1}, \ldots \int C_{n}\right\}[W([\xi])]^{\top}=\left\{\left(\int G_{0}-m_{0} \Delta C_{0}\right), \ldots\left(G_{n}-m_{n} \Delta C_{n}\right)\right\}$ 
where we have introduced the short-hand notation:

$$
\int C_{i} \equiv \int_{t_{1}}^{t_{2}} C_{i} d t ; \int G_{i} \equiv \int_{t_{1}}^{t_{2}} G_{i} d t ; \Delta C_{i} \equiv C_{i}\left(t_{2}\right)-C_{i}\left(t_{1}\right)
$$

Here, we must introduce a separate unknown time, $\xi$, for each element of the mass transport matrix:.

$$
[\mathbf{W}([\xi])]^{\top} \equiv\left[\begin{array}{cccc}
W_{00}\left(\xi_{00}\right) W_{10}\left(\xi_{10}\right) & \ldots & W_{n 0}\left(\xi_{n 0}\right) \\
W_{01}\left(\xi_{01}\right) & W_{11}\left(\xi_{11}\right) & \ldots & W_{n 1}\left(\xi_{n 1}\right) \\
\ldots & \ldots & \ldots & \ldots \\
W_{0 n}\left(\xi_{0 n}\right) W_{1 n}\left(\xi_{1 n}\right) & \ldots & W_{n n}\left(\xi_{n n}\right)
\end{array}\right]
$$

In the integral formulation the $\int C_{i}$ 's, $\int G_{i}$ 's, $\Delta C_{i}$ 's, and, now, the $\xi_{i j}$ which depend upon the nature of the measured data, constitute a data set. As before, to distinguish one data set, $i$, from all others we shall use a superscript $i$ as follows:

$$
\begin{gathered}
\text { Integral Data Set } i \\
\left\{\int C_{0}^{i}, \int C_{1}^{i}, \ldots \int C_{n}^{i}\right\},\left\{\Delta C_{0}^{i}, \Delta C_{1}^{i}, \ldots \Delta C_{n}^{i}\right\},\left\{\int G_{0}^{i}, \int G_{1}^{i}, \ldots \int G_{n}^{i}\right\},\left[\xi^{i}\right]
\end{gathered}
$$

If $(n+1)$ integral data sets are collected satisfying the condition:

$$
\left[\mathbf{W}\left(\left[\xi^{0}\right]\right)\right] \cong\left[\mathbf{W}\left(\left[\xi^{1}\right]\right)\right] \cong\left[\mathbf{W}\left(\left[\xi^{2}\right]\right)\right] \cong \ldots\left[\mathbf{W}\left(\left[\xi^{n}\right]\right)\right] \equiv[\overline{\mathbf{W}}]
$$

then, and only then, we may assemble a system of equations to determine the elements of the mass transport matrix as:$$
\left[\begin{array}{c}
\left\{\int C_{0}^{0}, \int C_{1}^{0}, \ldots \int C_{n}^{0}\right\} \\
\left\{\int C_{0}^{1}, \int C_{1}^{1}, \ldots \int C_{n}^{1}\right\} \\
\ldots \\
\left\{\int C_{0}^{n}, \int C_{1}^{n}, \ldots \int C_{n}^{n}\right\}
\end{array}\right]\left[\begin{array}{cccc}
\bar{W}_{00} & \bar{W}_{10} & \ldots & \bar{W}_{n 0} \\
\bar{W}_{01} & \bar{W}_{11} & \ldots & \bar{W}_{n 1} \\
\ldots & \ldots & \ldots & \ldots \\
\bar{W}_{0 n} & \bar{W}_{1 n} & \ldots & \bar{W}_{n n}
\end{array}\right]=\left[\begin{array}{c}
\left\{\left(\int G_{0}^{0}-m_{0} \Delta C_{0}^{0}\right), \ldots\left(\left\{G_{n}^{0}-m_{n} \Delta C_{n}^{0}\right)\right\}\right. \\
\left\{\left(\int G_{0}^{1}-m_{0} \Delta C_{0}^{1}\right), \ldots\left(\int G_{n}^{1}-m_{n} \Delta C_{n}^{1}\right)\right\} \\
\ldots \\
\left\{\left(\int G_{0}^{n}-m_{0} \Delta C_{0}^{n}\right) \ldots\left(\left(G_{n}^{n}-m_{n} \Delta C_{n}^{n}\right)\right\}\right.
\end{array}\right]
$$

To simplify notation we shall represent equation (24a) as:

$$
\left[\int \mathrm{C}\right][\overline{\mathrm{W}}]^{\top}=\left[\int \mathrm{T}\right]
$$

The integral concentration matrix, $\left[\int \mathrm{C}\right]$, would be formed from measured tracer concentration data; the integral tracer matrix, [ $[\mathrm{T}]$, would be formed from the known tracer injection amounts corrected by the " $\mathrm{m} \Delta \mathrm{C}$ " accumulation term. This set of equations defines the integral inverse (contaminant dispersal) problem.

It must be emphasized that the formulation of the integral inverse problem depends critically on the condition imposed by the integral mean value theorem, equation (23). In practical 
situations we should expect system airflows to vary with time. If all airflows in the system do not vary greatly over the time period spanning all integral time intervals used to evaluate the $(n+1)$ data sets, then this condition will essentially be met. If the flow variation is a high frequency variation (i.e., relative to the time period spanning all time intervals used to evaluate the $(n+1)$ data sets and the dominant time constant of the system) then we should expect the condition of equation (23) will be met and, furthermore, the mass transport matrix will correspond to a mean flow condition in the system.

Practically speaking, then, to be able to apply the integral inverse formulation to tracer analysis with confidence, we should employ tracer injection and data collection strategies that may be completed rapidly. Both the pulse injection strategy and a integral constant injection strategy can meet this objective, especially if multiple tracers are employed.

\section{Singularity and Conditioning of the Inverse Formulations}

Although equations (20) and (24) appear to have the form of a determined system of equations (i.e., $(n+1)$ equations of $(n+1)$ sets of $(n+1)$ unknowns for $(n+1)$ sets of right hand sides), they will yield solutions (i.e., be nonsingular) only if they describe $(n+1)$ linearly independent equations. From the theory of linear systems of algebraic equations we know that linear independence, or nonsingularity, will be realized if the concentration matrix, [C], for equation (20), or the integral concentration matrix $[j \boldsymbol{C}]$, for equation (24), consists of linearly independent row vectors. We shall, therefore, consider this a necessary condition that must be met by any tracer gas technique.

Even if these row vectors can be shown to be linearly independent, in principal, "nearsingularity" may still result, due to the limitations of finite-precision calculations, that will manifest itself in terms of the conditioning of the inverse problem and result in, possibly, unacceptable error in the determination of the elements of the mass transport matrix. That is to say, if the row vectors are "nearly" dependent due to measurement error, a poor measurement and injection strategy, and/or the intrinsic character of the building idealization being studied ${ }^{2}$, then the resulting system of inverse equations will be ill-conditioned ${ }^{3}$ and results obtained from them may be overwhelmed by error.

In principal, a well-conditioned system of inverse equations can be formed if a tracer injection strategy is chosen that will not only result in linearly independent row vectors but data sets that satisfy the orthogonality condition:

$$
\left\{C^{i}\right\}^{\top}\left\{C^{i}\right\}=0 ; i, j=1,2, \ldots n ; i \neq j
$$

for the instantaneous form, or

$$
\left\{\int C^{i}\right\}^{\top}\left\{C^{j}\right\}=0 ; i, j=1,2, \ldots n ; i \neq j
$$

for the integral form. One could achieve this objective if one could identify a tracer injection strategy that would result in measurable concentrations in a single zone and zero concentrations in all others, that is one that would result in $n$ row vectors of the form:

$$
\left.\begin{array}{ccc}
i^{\text {th }} \text { elem. } \\
\downarrow \\
1 & \ldots & 0
\end{array}\right\}=C^{i}\left\{e_{i}\right\}^{\top}
$$

2 For example, idealizing two building volumes having very large air exchange rates with each other as separate, well-mixed zones, rather than a single well-mixed zone, will lead to a poorly conditioned inverse problem.

${ }^{3}$ An ill-conditioned problem is one for which relative errors in the data defining the problem will tend to become amplified to result in larger relative errors in the solution of the problem. 
for the instantaneous case, or:

$$
\begin{aligned}
& i^{\text {th }} \text { elem. } \\
& \left\{\int c^{i}\right\}^{\top}=\int C^{i}\left\{\begin{array}{lllll}
1 & \ldots & 1 & \ldots & 0
\end{array}\right\}=\int C^{i}\left\{\mathbf{e}_{i}\right\}^{\top}
\end{aligned}
$$

for the integral case, where $\mathrm{C}^{i}$ and $\int \mathrm{C}^{i}$ are scalars and $\left\{\mathrm{e}_{\mathrm{i}}\right\}$ is a vector with a unit value for element $i$ and zero values elsewhere. (For conditions of steady flow the orthogonality conditions of equations (25) and (26) would be met by utilizing the system eigenvectors, but steady flow conditions will not in general prevail and the analyst will, in any event, have no a priori knowledge of these eigenvectors.)

It will not, in general, be possible to achieve this end. One may, however, approach this goal practically by exciting each zone with an individual tracer injection so that, presumably, the concentration response in the excited zone will be greater than that in all others. This strategy must be considered fundamental to any multi-zone tracer gas technique, and has been used as the basis of the multi-zone constant injection tracer technique and the pulse injection technique.

\section{Conservation of Air Mass Flow}

Regrettably, one zone, the exterior "zone", which will be involved in all real building idealizations, can not be excited by tracer injection (due to its practically infinite volume it tends to act as a constant concentration sink) and, therefore, in applying the individual zone injection strategy, we will find ourselves short by one data set. By demanding, however, the conservation of total air mass flow we may obtain this needed $(n+1)$ th equation.

The conservation of total mass flow may be conveniently realized by recognizing that the mass concentration for air in all zones is unity and unchanging. The instantaneous data set for air alone is:

$$
{ }^{\text {air }} C_{i}=1 ; \quad \frac{d^{\text {air }} C_{i}}{d t}=0 ; \quad{ }^{\text {air }} G_{i}=0
$$

and, the integral data set for air alone:

$$
\int{ }^{\text {air }} C_{i}=1 \Delta t ; \Delta^{\text {air }} C_{i}=0 ; \int^{\text {air }} G_{i}=0 ; \Delta t=\left(t_{2}-t_{1}\right)
$$

Using these data sets we obtain the first of the required $(n+1)$ equations:

$$
\{1,1, \ldots 1\}\left[\begin{array}{cccc}
w_{00} & w_{10} & \ldots & w_{n 0} \\
w_{01} & w_{11} & \ldots & w_{n 1} \\
\ldots & \ldots & \ldots & \ldots \\
w_{0 n} & w_{1 n} & \ldots & w_{n n}
\end{array}\right]=\{0,0, \ldots 0\}
$$

for the instantaneous form of the inverse analysis equations, and

$$
\{1,1, \ldots 1\}\left[\begin{array}{cccc}
\bar{W}_{00} & \bar{W}_{10} & \ldots & \bar{W}_{n 0} \\
\bar{W}_{01} & \bar{W}_{11} & \ldots & \bar{W}_{n 1} \\
\ldots & \ldots & \ldots & \ldots \\
\bar{W}_{0 n} & \bar{W}_{1 n} & \ldots & \bar{W}_{n n}
\end{array}\right]=\{0,0, \ldots 0\}
$$


for the integral forms of the inverse analysis equations.

\section{The Tracer Rate and Integral Tracer Matrices}

The formation of the tenns of the tracer rate and integral tracer matrices, [ $T$ ] and [ $\mathrm{T}$ ], corresponding to the exterior environment:

$$
\left(G_{0}^{i}-m_{0} \frac{d C_{0}^{i}}{d t}\right) \text { and }\left(\int G_{0}^{i}-m_{0} \Delta C_{0}^{i}\right) ; i=1,2, \ldots n
$$

presents a problem since the mass of air in the exterior zone, $m_{0}$, is considered infinite. In practice, however, it will not be reasonable to inject tracer into the exterior zone directly thus we may assume $G_{0}$ to be zero and, therefore, requiring conservation of tracer mass for each data set we may conclude that:

$m_{\sigma} \frac{d C_{0}^{i}}{d t}=\sum_{j=1}^{n}\left(G_{j}^{i}-m_{i} \frac{d C_{j}^{i}}{d t}\right)$

$m_{0} \Delta C_{0}^{i}=\sum_{j=1}^{n}\left(\int G_{j}^{i}-m_{j} \Delta C_{j}^{i}\right)$

That is to say, the infinitesimal change in concentration of the infinite exterior mass is simply equal to the net (rate of) generation of tracer less the net (rate of) accumulation tracer (i.e., the first term of each row of the tracer rate and integral tracer matrices is simply equal to the sum of the other terms in the row which are readily determined from the measured data sets).

This resolves the practical problems of accounting for the infinite mass of the exterior zone and we are now in a position to consider collecting the additional $n$ equations needed to form a complete inverse problem. Two approaches will be considered; the first based upon a pulse injection strategy and the second on a constant injection strategy.

\section{Multi-Zone Pulse Tracer Injection Strategy}

A multi-zone pulse injection of tracer may be employed to obtain a sufficient number of equations to formulate a complete inverse analysis problem. The injection and measurement strategy used for the multi-zone pulse injection technique is illustrated below in Figure 10 for a three-zone case. We first subject one zone to an individual, short-duration tracer pulse and measure the tracer concentration responses in all zones. A second zone is excited and, again, we measure the responses in all zones. The process of excitation and response measurement is continued until all zones have been independently pulsed. These independent zone pulses may, conceivably, be done in series using a single tracer, done simultaneously using multiple tracers, or done as a series of multiple-tracer pulses.

If we feel confident that the condition of equation (23) has been realized experimentally (i.e., airflows in the system have remained more or less constant during the test time period) we may then directly substitute the measured data into equation (24) to form a complete inverse problem. As each zone is injected individually, the integral tracer matrix, $\left[\int\right]$, will have generation integral contributions, $\int G$, only along the diagonal; the off diagonal terms will involve only $\mathrm{m} \Delta \mathrm{C}$ contributions. As in the single-zone case, for each data set we may consider arbitrary time intervals of integration - complete purging of the system is not required if we carefully 


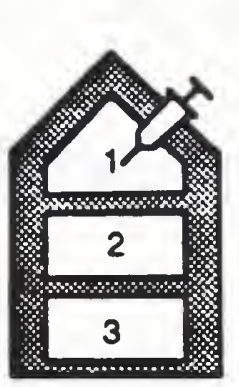

Zone 1

Pulse

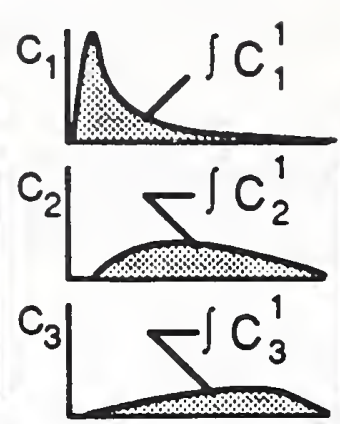

Zone 2

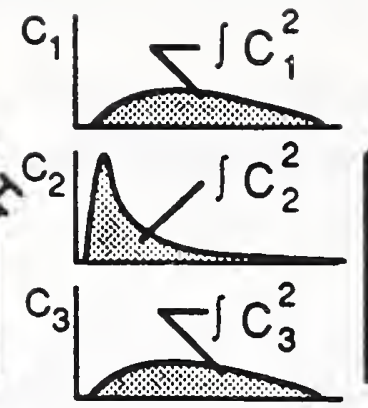

Pulse

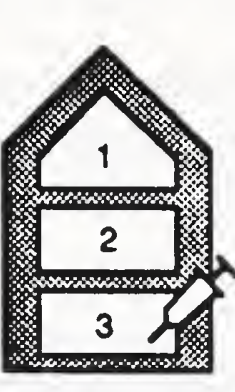

Zone 3

Pulse

\section{Fig. 10 Multi-Zone Pulse Injection Technique}

Nonsingularity of the Integral Concentration Matrix [ $\left.\int \mathrm{C}\right]$ : If the pulse injected into zone i is of a relatively short duration (i.e., the pulse duration is small relative to the smallest system time constant, approaching, in effect, an impulse excitation) then, given the assumption of wellmixed zones, the pulse will create an initial concentration in zone i equal to the amount of tracer injected, li, divided by the mass of the air in zone $i, m_{i}$. That is to say, the pulse will establish an initial concentration condition:

$\left\{C^{i}(t=0)\right\}=\left(\frac{p^{i}}{m_{i}}\right)\left\{e_{i}\right\} ; \quad j \equiv \int_{0}^{t} G^{i}(t) d t$

where the superscript $i$ is used to indicate data set $i$ and, as before, $G^{i}(t)$ is the pulse injection time history for zone $i$. From the theory of systems of differential equations we obtain the decay response of the system to this initial condition, for constant flow conditions, as:

$\left\{C^{i}(t)\right\}=\exp (-[\tau] t)\left(\frac{1}{m_{i}}\right)\left\{e_{i}\right\} ;[\tau] \equiv[M]^{-1}[W]$

where $[\tau]$ is sometimes called the state matrix of the system. Integrating this expression over the time interval $\left(t_{1}, t_{2}\right)$ we obtain a general expression for the rows (transposed) of the integral concentration matrix, $\left[\int \mathcal{C}\right]$, as;

$\int_{t_{1}}^{t_{2}}\left\{C^{i}(t)\right\} d t=[\tau]^{-1}\left[\left[\exp \left(-[\tau] t_{1}\right)\right]-\left[\exp \left(-[\tau] t_{2}\right)\right]\left(\frac{p^{i}}{m}\right)\left\{e_{i}\right\}\right.$

The state matrix $[\tau]$ will be nonsingular for system idealizations that satisfy continuity of total airflow (i.e., real systems) [see Axley 87, or 88a] and, therefore, it follows that both $[\tau]^{-1}$ and $\exp (-[\tau] \mathrm{t})$, for all $\mathrm{t}$, will also be nonsingular. As a result, the product matrix on the right hand side of equation (33) will be nonsingular or, equivalently, will consist of linearly independent column vectors. The unit vector $\left\{e_{i}\right\}$ acts, then, to select one of these independent column vectors which when then scaled by the initial concentration $\left(1 / / m_{i}\right)$ forms the ith row (transposed) of the integral concentration matrix [ $[\mathbf{C}]$. We may conclude then that the integral 
concentration matrix $\left[\int C\right]$ will be nonsingular (i.e., have independent rows) when a) flow is steady, b) an equivalent integration time interval (relative to the pulse injection) is used to integrate the concentration responses for all pulses, and c) the independent zone pulse strategy is employed. In the practical application of the pulse injection technique we select time intervals so that, presumably, condition a) and b) are substantially satisfied.

\section{Constant Injection Tracer Injection Strategy}

Another approach to obtain the needed equations to formulate a complete inverse analysis problem involves the constant injection strategy. In the ideal application of the constant injection technique each zone is subjected to an independent constant injection of tracer, and when the concentration in all zones becomes steady, they are measured to form a single concentration data set. This is repeated for all zones, as illustrated below in Figure 11, the concentration matrix [C] is formed from this measured data, and equation (20) is solved for the unknown airflows assuming steady conditions prevail (i.e., setting all moC/dt terms equal to zero). To independently inject each zone and yet measure steady state concentrations in all zones for each of the independent injections requires the simultaneous injection of multiple tracers, one for each zone.

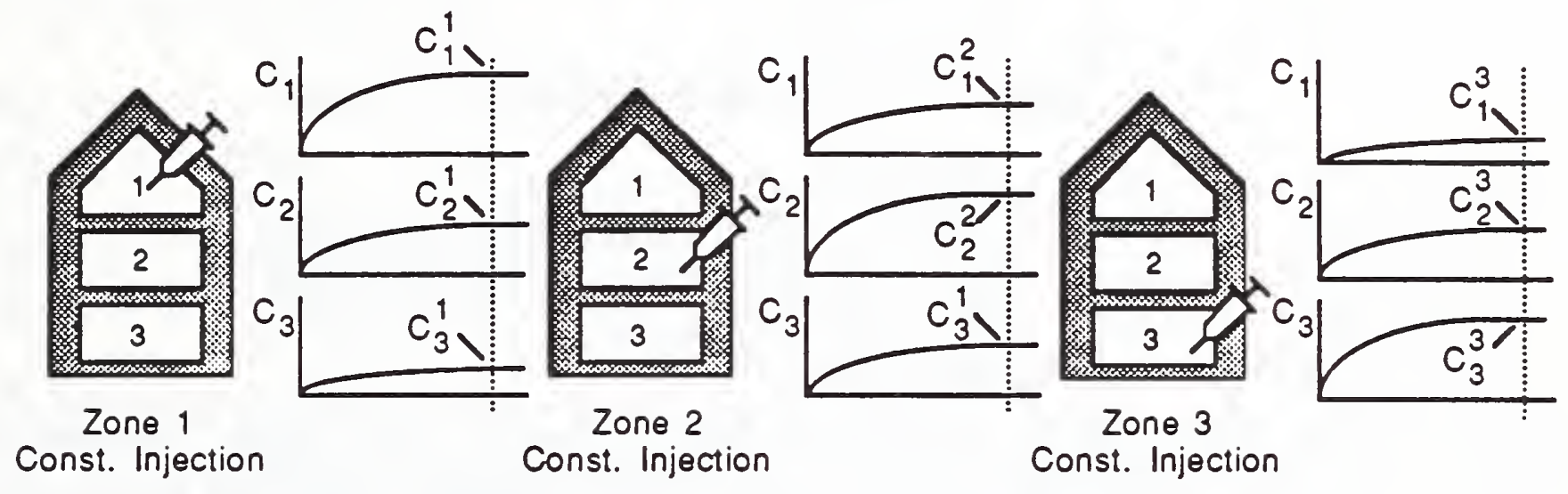

Fig. 11 Multi-Zone Constant Injection Technique

Nonsingularity of the Concentration Matrix [C]: If flow conditions are steady in the building system, we may obtain an expression for the concentration response to a constant injection in zone i, Gi, directly from equation (14) as:

$\left\{C^{i}(t)\right\}=[W]^{-1} G^{i}\left\{e_{i}\right\}$

[W], and hence $[W]^{-1}$, will be nonsingular for system idealizations that satisfy continuity of total airflow (i.e., real systems) and, therefore, will have independent column vectors. Again the unit vector, $\left\{e_{i}\right\}$, that mathematically defines the individual zone injection strategy, acts to select one of the independent columns of $[W]^{-1}$, which is then scaled by $G^{i}$ to form one of the rows (transposed) of the concentration matrix. We may conclude, then, that the concentration matrix [C] will be nonsingular for the ideal conditions of constant airflow in the building system.

\section{Integral Constant Injection Technique}

As discussed earlier, in many practical situations the airflows in the building system will seldom remain constant long enough to achieve a steady state response. Therefore, it has become common practice to use average concentration measurements, taken over a relatively long time period, for the concentration data sets needed in equation (20). Using average values is completely equivalent to using integral data sets and, therefore, these values should be used in conjunction with the integral formulation of the problem, equation (24), rather than the 
instantaneous form equation (20), but to do so we must be careful to satisfy the condition defined by equation (23) - a condition that, practically speaking, requires consideration of relatively short integration time intervals (i.e., averaging periods). For situations where airflow is likely to be nonconstant, then, one should use a integral constant injection tracer technique based upon equation (24), accounting for the $\mathrm{m} \Delta \mathrm{C}$ accumulation due to unsteady flow conditions and employing relatively short integration time intervals to assure the satisfaction of the condition of equation (23). The injection and measurement strategy used for the multi-zone integral constant injection technique is illustrated below in Figure 12 for a three-zone case.

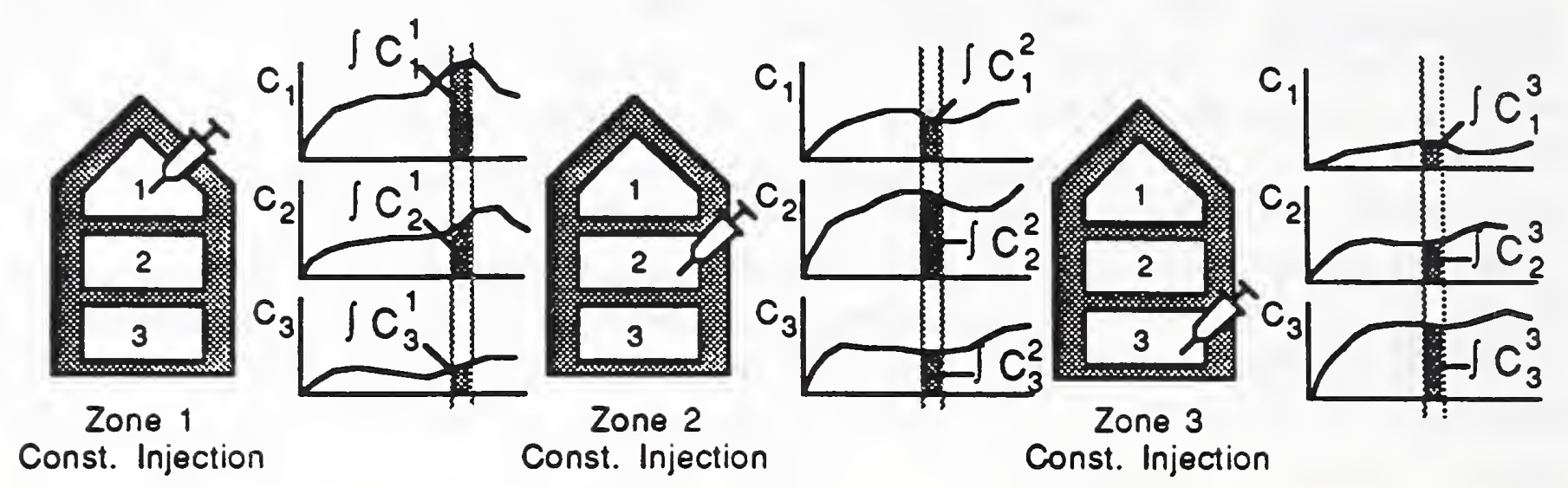

Eig. 12 Multi-Zone Integral Constant Injection Technique

Solution of the Inverse Analysis Equations and Error Evaluation:

Errors in the estimation of airflows by tracer techniques may be attributed to;

a) an inappropriate idealization of the building system being investigated,

b) uncertainties introduced via flow variations, and/or

c) error introduced via measurement error.

The idealization of a given building airflow system may, to a great extent, determine the success or failure of the application of tracer techniques to the determination of airflows in the building. For example, the idealization of a very well-mixed portion of a building system as a collection of multiple zones will, in itself, result in a poorly conditioned system of inverse equations that will tend to amplify measurement error. Although we attempt to provide some guidance in this paper we are forced to admit that the process of system idealization remains an art that requires considerable experience and skill.

It was shown that in the single-zone case flow variation could result in very large errors in the estimation of mean airflows. It must be expected that even greater errors will result in multi-zone cases due to the numerical phenomena of ill-conditioning that is intrinsically associated with the inverse problems being considered here. It is the primary responsibility of the analyst, then, to attempt to conduct a given tracer test in such a way that the underlying assumptions of the tracer technique are satisfied. With this done, numerical techniques exist to deal with solution errors resulting from measurement error.

The inverse problem defined by either equations (20) or (24), or their specific applications to the pulse injection, constant injection, or integral constant injection techniques must be expected to be ill-conditioned and, therefore, must be solved with special care to avoid unnecessary amplification of data errors. Conventional elimination or iterative equation solving techniques may be expected to fail for very ill-conditioned problems and, thus, the analyst is well-advised to employ numerically more stable algorithms. Singular value decomposition has become the method of choice for solving ill-conditioned problems and is recommended here [Press 86]. (Solution techniques based upon Cramer's Rule are always computational inferior to the elimination and iterative techniques and should, therefore, not be considered).

Furthermore, as the degree of ill-conditioning that might be associated with any given problem will not, in general, be evident, the analyst is well-advised to not only compute the 
solution to the inverse problem; but also compute (and report) a measure of error associated with the solution. D'Ottavio [87] and Walker [85] have discussed error analysis techniques relating to the solution of both the constant injection technique and the pulse injection technique (Walker's decay integral method); their results apply here as well. Three error estimation techniques are offered; a) error estimation based upon perturbation analysis of systems of linear equations involving vector and matrix norms, b) error estimation based upon Monte Carlo error analysis, and c) error estimation based upon first order error analysis using Taylor expansions. The first approach provides an upper-bound error estimation. As this approach is sensitive to the scaling of the inverse equations, D'Ottavio employed optimal scaling of the equations, based upon scaling individual equations by the inverse of their row Euclidean norm, in conjunction with this approach to provide a (near) minimum upper bound error estimation.

Central to perturbation analysis of systems of linear equations is the so-called condition number, which, in simple terms, provides an upper bound estimate of the ratio of the maximum relative solution error to the maximum relative data error (i.e., an error amplification factor). Thus, reporting the condition number of the concentration matrix, [C], (integral concentration matrix, [ $\mathrm{C}]$ ) provides one means to characterize the error associated with the solution of a given problem. This condition number is conveniently computed as a by-product of singular value decomposition.

\section{Application of the Multi-Zone Pulse Injection Technique Measurement Method}

The pulse techniques presented above provide flexible tools for the determination of building airflow rates, however, their successful application in a particular building requires the user to understand the building and its systems. Based on this understanding the user develops an "idealization" of the building as a series of zones and formulates the pulse experiment in order to determine specific airflow rates between these zones. This process of applying the pulse technique to a particular building consists of qualitative and quantitative aspects. The method begins with a qualitative analysis of the building layout and the ventilation system equipment and zoning. The major zones and system airflow paths of the building are identified, and the existence of unexpected or undesired airflows due to envelope leakage, poor system performance or inadequate separation between zones are investigated. A qualitative airflow diagnosis, using hand-held instrumentation (e.g. anemometers), "smoke-sticks", or tracer gas pulses, can serve to further elucidate the building's airflow characteristics. For example, exhaust airflows may be verified as such or shown to be not flowing in the expected direction. In addition, certain airflows may be shown to be zero, and need not be included in the idealization.

Based on the qualitative analysis and the particular airflows that the experimenter is interested in, a system or subsystem idealization of the building is developed. This idealization consists of a series of well-mixed zones connected by airflow paths. The idealization need not include every airflow and every zone in the building. In fact, such an all-inclusive model of a building will generally be unmanageably complex from an experimental point of view and involve the determination of more airflow rates than are necessarily of interest. In certain circumstances, a selected subsystem of the building can be investigated, providing information without consideration of the rest of the building.

Once the building idealization has been developed, the quantitative experimental analysis of this system is conducted. One must define tracer gas injection and air sampling strategies, in conjunction with one's data collection and analysis approaches. The injection strategy includes the manner in which the tracer will be delivered to each zone, the amount of tracer to be injected and a means for determining this amount, and the timing of the injections into the various zones. The air sampling strategy includes the number and location of air sampling points in each zone, and the manner in which they will be sampled (real-time monitoring or container averaging). 
Real-time monitoring must be conducted with consideration given to the sampling frequency of the tracer gas monitor and the transport of air samples from the sampling locations to the monitor. Once the data is collected it is converted into the form of equation (24), one row for each tracer gas injection, which is then solved for the unknown airflows and analyzed to provide some evaluation of error. In the studies considered below the solution was achieved using the robust and stable numerical method known as singular value decomposition [Press 86] and the error was characterized by the condition number of the system which is obtained as a byproduct of the singular value decomposition.

\section{Measured Results: NBS Office Building Studies}

Two examples of the application of integral pulse techniques to a fifteen-story office building in Washington, DC are presented. This building has four separate air handlers serving the fifteen-story tower section, two for the fourteenth and fifteenth floors, and two more serving floors one through thirteen. These air handlers run on $100 \%$ outdoor air and are located in a penthouse mechanical room. The air from the building is exhausted through a relief air system directly to the outdoors, with no provision for the recirculation of return air. On each floor, air from the supply air ducts is forced into a ceiling plenum from which it enters the occupied space through diffusers in the suspended ceiling as shown in Figure 13. Based on an on-site inspection of the building and its systems, it was noted that there were significant amounts of supply air leaking from the pressurized ceiling plenum to the relief air shafts, to other service shafts, and through the exterior envelope. This leakage led to the question of exactly how much of the supply air was actually reaching the occupied space on the floors. In addition, strong airflows were noted in the two stairways in the building, flowing up to the penthouse mechanical room.

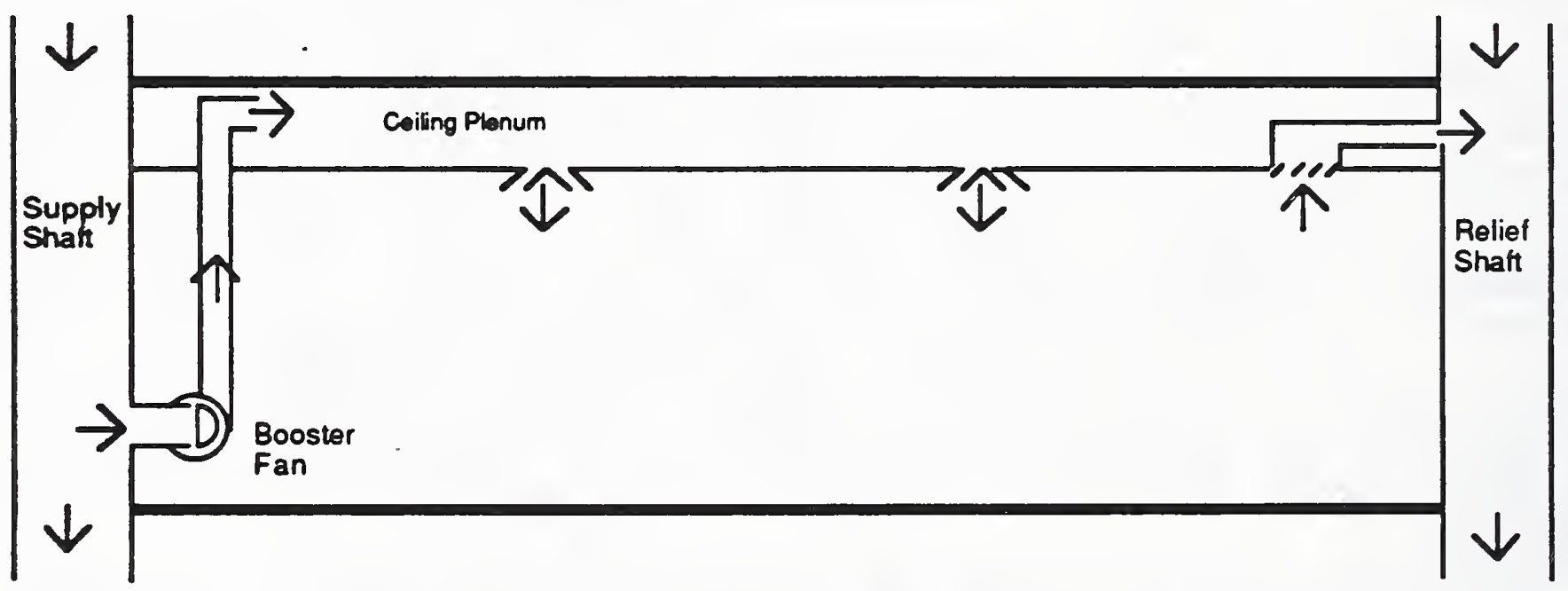

Fig 13 Simplified Section of an Individual Floor of Tower

Based on the inspection of the building and its systems, two different idealizations of the building were investigated with integral pulse tests. As shown in Figures 14 and 16 these idealizations include one of the whole tower and the penthouse, and the second is of an individual floor. In the first idealization, the tower is modeled as three building zones, based on the air handler zoning and the observed importance of the penthouse. Zone 1 consists of the penthouse mechanical room, the fourteenth and fifteenth floors are modeled as a single zone zone 2, and zone 3 idealizes floors three through thirteen. It must be emphasized that these groups of floors behave as single well-mixed zones only for the tracer injection strategy used in the tower tests (i.e., they respond with practically uniform concentrations for this particular injection strategy). For other injections or releases of contaminant these floors will, in general, behave differently. The second model is an example of a building subsystem that enables the investigation of limited aspects of the building's air exchange characteristics. This model is 
based upon the characteristics of an individual floor and its response to the tracer injection strategy used to study the floor. An individual floor is modeled as two zones, a supply zone and an occupied zone. The supply zone includes the supply air distribution system for a floor and the occupied zone includes the space below the suspended ceiling. The supply zone is a conceptualization, not a distinct physical volume that is contained between well-defined boundaries. Therefore, the mass of the supply zone can not be used in analyzing the data, that is the integrals corresponding to the supply zone injection must begin and end when the supply air concentration equals zero.

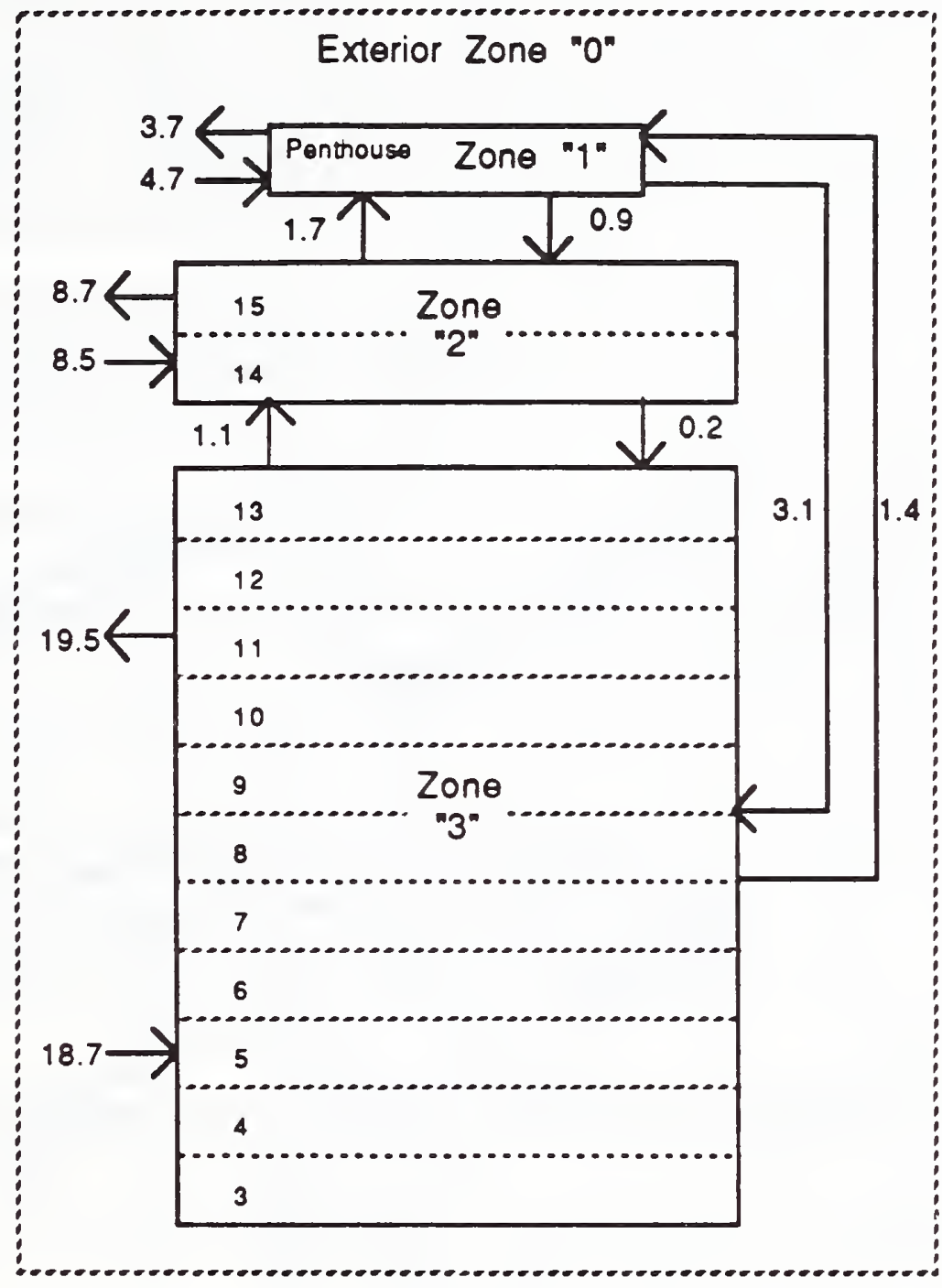

Condition Number $=3.9$

\section{Fig 14 Office Tower Three-Zone Idealization and Results for $12 / 1 / 87$}

(all flows $\mathrm{m}^{3} / \mathrm{s}$ )

The tower model depicted in Figure 14 was investigated using successive pulse injections of sulfur hexafluoride $\left(\mathrm{SF}_{6}\right)$ into the penthouse (zone 1 ), the fourteenth and fifteenth floors (zone 2), and floors three through thirteen (zone 3). A premeasured amount of $\mathrm{SF}_{6}$ was injected into the penthouse by hand while walking throughout the space over a period of about two minutes. The injections into the other two zones were made by injecting $\mathrm{SF}_{6}$ into the air handlers serving these zones through flowmeters at a known rate for a known length of time (about one minute). The penthouse concentration response was very short-lived and therefore the tracer gas injection period was included in the concentration integral. Because of leakage in the supply air distribution systems serving the building, the injection periods were not included in the integrals of the concentration response to the injections in zones 2 and 3 . The results of one of the tower pulse tests are shown in Figure 14. The airflow rates from the outdoors (zone 
0 ) into zones 2 and 3 include intentional outdoor air intake through the air handlers and the infiltration of air through leaks in the exterior envelope of the building. The airflow rate through the air handlers serving zone 2 is about $7 \mathrm{~m}^{3} / \mathrm{s}$, as measured with a duct pulse test, but not all of this supply air gets to the zone due to leaks in the supply air system. Therefore the difference between the measured airflow rate from the outdoors to zone $2,8.5 \mathrm{~m}^{3} / \mathrm{s}$, and the measured airflow rate through the air handlers is a lower limit on the infiltration airflow into zone 1 , i.e., $1.5 \mathrm{~m}^{3} / \mathrm{s}$ or about 0.5 air changes per hour. Similarly, the airflow rate through the air handlers serving zone 3 is about $20 \mathrm{~m}^{3} / \mathrm{s}$. Only $18.7 \mathrm{~m}^{3} / \mathrm{s}$ of outdoor airflow into zone 3 was measured, and therefore no estimate of the minimum infiltration rate into that zone can be made.

Using the measured flow rates and the known injection time histories, the concentration response of the tower was determined analytically using the program CONTAM87 [Axley 88a]. Predicted (modeled) concentration time histories are compared below, Figure 15, to measured values; the close agreement provides an indication of validation of the pulse injection technique.
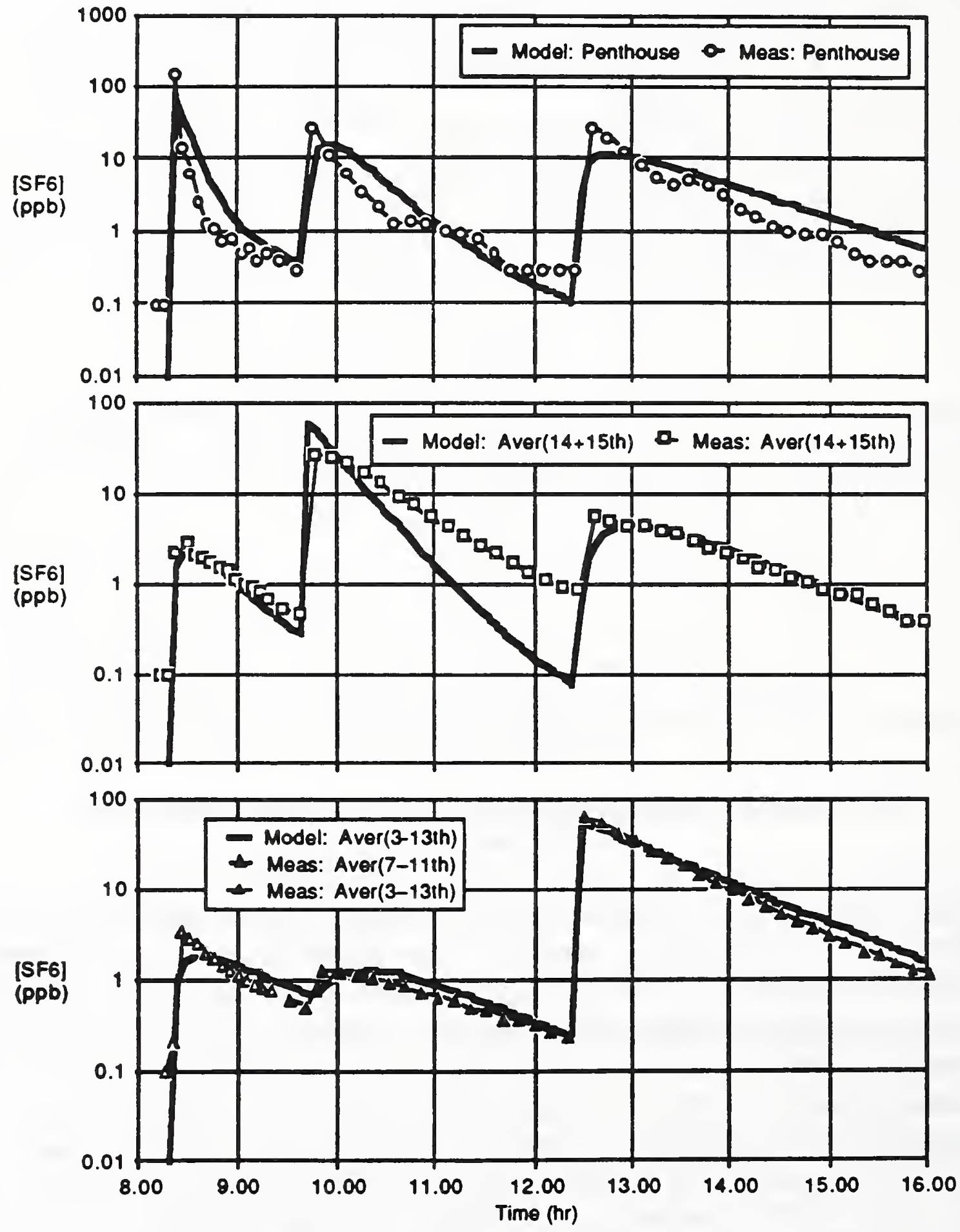

Fig. 15 Comparison of Measured and Predicted Response to Pulse Injections 
The floor model in Figure 16 was investigated with a pulse test in order to determine the amount of supply air that was bypassing the occupied space of the floor. In this idealization of a floor of this building, zone 0 includes the outdoors and the rest of the building, zone 1 is the supply air distribution system, and zone 2 is the occupied space of the floor. This idealization is appropriate because the floors of this building are well separated from each other in terms of airflow. During these tests the $\mathrm{SF}_{6}$ concentration was measured on the floors above and below the floor being tested, and there was essentially no $\mathrm{SF}_{6}$ on the surrounding floors. The injection into zone 1 was made by hand into the supply air ductwork, and the concentration response in this ductwork was determined by filling an air sample container to determine the average concentration. This was essentially a duct pulse test to determine the supply airflow rate to the floor, but the concentration response was also measured in real-time at four locations in the occupied space (zone 2). The integral of this concentration response obviously included the tracer gas injection period. The tracer gas injection into zone 2 was made by hand; a known amount of $\mathrm{SF}_{6}$ was released throughout the occupied space. Since there was no backflow from the occupied space into the supply air system there was no need to measure the concentration response in zone 1. The results for a set of repeated "floor-bypass" tests are presented in Figure 16. These results are based upon a series of three injection tests; the supply zone was injected once and the occupied space was subjected to two separate injections. The test $A$ results were computed using concentration data for the single supply zone injection and the first of the occupied space injections; the test B results were computed using concentration data for the supply zone injection and the second of the occupied space injections. A comparison of these results provides an indication of the uncertainty of the computed flows. During this test, and during other tests on this and other floors of the building, it was found that a significant percentage of the supply air intended for this floor does not reach the occupied space. The supply air "bypasses" the occupied space due to several leaks in the pressurized ceiling supply air plenum that allow the supply air to flow into the relief air system, service shafts in the building, and the outdoors instead of through the ceiling diffusers into the occupied space.

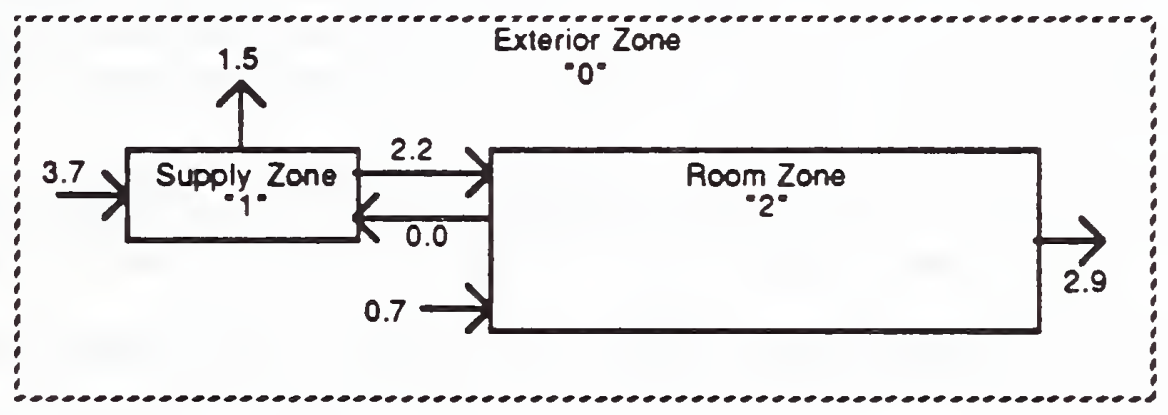

Test A Results

Condition Number $=3.2$

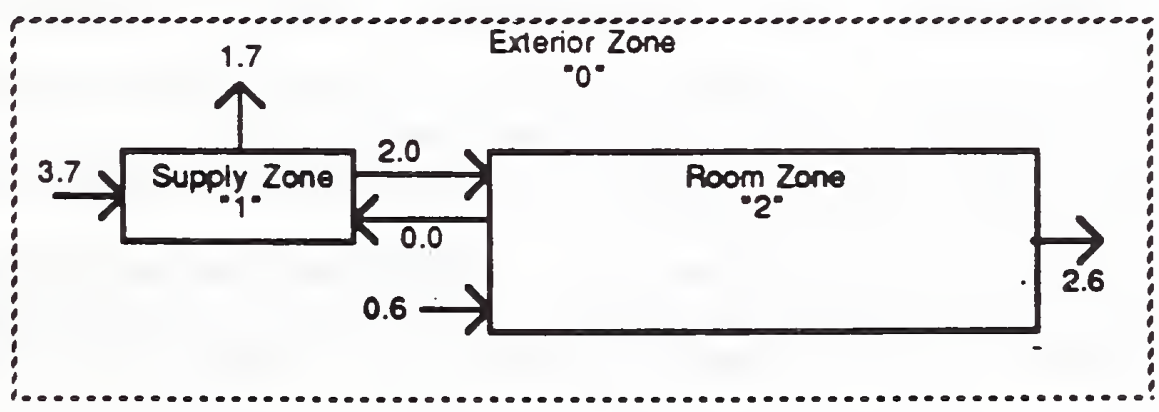

Test B Results

Condition Number $=3.4$

Fig. 16 Individual Floor Idealization and Results for Repeated Tests of 12/17/87 (all flows $\mathrm{m}^{3} / \mathrm{s}$ ) 


\section{CONCLUSION}

The pulse injection tracer techniques, based on integral mass balance formulations, provide useful tools for studying building airflow systems. The duct pulse application provides a rapid and convenient means of measuring airflows in ducts. The building pulse applications are capable of determining airflow rates in multi-zone building systems in relatively short time periods (i.e., time periods on the order of the dominant system time constants), and can be employed with a single tracer gas. Pulse injection determinations of airflow rates may be expected to be relatively insensitive to variations in airflow rates, and the analysis of data from field studies to date indicate that the multi-zone pulse injection technique may be expected to yield relatively well-conditioned equations. In the multi-zone pulse injection technique, as in all multi-zone tracer gas techniques, the manner in which the building airflow system is idealized as a series of inter-connected zones is pivotal in obtaining a well-conditioned system of equations and, thereby, reasonable estimates of the system airflow rates.

The development of the pulse injection techniques has implications for other tracer gas measurement approaches. Integral mass balance relations should be applied to existing tracer injection strategies to provide alternate formulations and, possibly, to identify strategies of minimizing errors in the determination of airflow rates. An integral formulation of the constant injection technique, which, in principal, should avoid some of the problems of the technique as commonly used, was presented and should be considered further. The pulse injection techniques themselves require additional study in both laboratory and field settings to more completely examine sources of errors and to better establish experimental procedures for their practical application.

\section{REFERENCES}

Afonso, C.F.A., Maldonado, E.A.B., \& Skäret, E., "A Single Tracer-gas Method to Characterize Multi-room Air Exchanges," Energy and Buildings, Vol. 9, Elsevier Sequoia, The Netherlands, 1986, pp. 273-280

Afonso, C.F.A., \& Maldonado, E.A.B., "A Tracer-Gas Procedure for the Simultaneous Evaluation of Effective Volumes and Multizone Airflows," Proceed. 3rd International Congress on Building Energy Management, Lausame, Switzerland, Sept., 1987

Afonso, C.F.A., Maldonado, E.A.B., \& Skáret, E., "Measuring Indoor Air Movement: An Essential Task to Characterize Indoor Air Quality," Proceed. IAQ '86, ASHRAE, Atlanta, GA, Apr., 1986, pp. 592-601Axley, James, Indeor Air Quality Modeling: Phase II Report NBSIR 87-3661, CBT, National Bureau of Standards, Gaithersburg, MD, Oct, 87

Axley, J., Indoor Air Quality Modeling: Phase لI Report. NBSIR 87-3661, CBT, National Bureau of Standards, Gaithersburg, MD, October., 87

Axley, J., Progress Toward a General Analytical Method for Predicting Indoor Air Pollution in Buildings: Indoor Air Quality Modeling: Phase III Report, NBSIR 88-3814, CBT, National Bureau of Standards, Gaithersburg, MD, June, 88

Axley, J., Multi-Zone Dispersal Analysis by Element Assembly, (submitted for publication to Building and Environment, May 1988)

Bohac, D., Harrje, D.T., \& Horner, G.S., "Field Study Comparisons of Constant Concentration and PFT Infiltration Measurements," Proceed. of 8th AIVC Confer., Uberlingen, Germany, Sept., 1987

Dick, J.B., "Experimental Studies in Natural Ventilation of Houses," Journal of the Institute of Heating and Ventilating Engineers, England, Dec., 1949, pp. 421.466

Dietz, R.N., Goodrich, R.W., Cote, E.A., \& Wieser, R.F., "Detailed Description and Performance of a Passive Perfluorocarbon Tracer System for Building Ventilation and Air Exchange Measurements, "Measured Air Leakage of Buildings, ASTM Special Technical Publication 904, Trechsel, H.R., Trechsel, H.R., \& Lagus, P.L., Editors, ASTM, Phil., PA, 1986

D'Ottavio, T.W., Senum, G.I., \& Dietz, R.N., "Error Analysis Techniques for Perfluorcarbon Tracer Derived Multizone Ventialtion Rates," BNL 39867, Brookhaven National Laboratory, June, 1987

I'Anson, S.J., Irwin, C., \& Howarth, A.T., "Air Flow Measurement Using Three Tracer Gases," Building and Environment, Pergamon Press, Great Britain, Vol. 12, No. 4, 1982, pp.245-252

Irwin, C., Edwards, R.E., \& Howarth, A.T." "The Measurement of Airflows Using a Rapid Response Tracer Gas Technique," Building Services Engineering Research and Technology, Vol. 6, No. 4, 1985, pp. 146-152 
Jensen, L., "Determination of Flows and Volumes in Multiple Cell Systems," IEAA AIVC Newletter, Vol. 9, No. 2. Berkshire, England, Feb., 1988, pp. 4-6

Lagus, P. \& Persily, A.K., "A Review of Tracer-Gas Techniques for Measuring Airflows in Buildings," ASHRAE Transactions, Vol. 91, Pt. 2. 1985, pp. 1075-1087

Lawrance, G.V. \& Waters, J.R., "Measurements of Infiltration and Air Movement in Five Large Single-Cell Buildings," Proc. 8th AIVC Confer., Uberlingen, Germany, Sept, 1987, pp. 2.1-2.18

Nauman, E.B. \& Buftham, B.A., Mixing in Continuous Flow Systems, John Wiley \& Sons, NY, 1983

Penman, J.M. \& Rashid, A.A.M., "Experimental Determination of Air-flow in a Naturally Ventilated Room Using Metabolic Carbon Dioxide," Building and Environment, Pergamon Press, Great Britain, Vol. 17, No. 4, 1982

Perera, M.D.A.E.S., "Review of Techniques for Measuring Ventilation Rates in Multi-Celled Buildings," Proc. of EEC Contractors Meeting on Natural Ventilation, Brussels, Sept., 1982

Press, W.H., Flannery, B.P., Teukolsky, S.A., \& Vetterling, W.T., Numerical Recipes: The Art of Scientific Computing, Cambridge University Press, Cambridge, 1986

Sandberg, M., "The Use of Moments for Assessing Air Quality in Ventilated Rooms," Building and Environment, Vol. 18, No. 4, Pergamon Press, Great Britain, 1983 pp. 181-1978

Sandberg, M., "The Multi-Chamber Theory Reconsidered from the Viewpoint of Air Quality Studies," Building and Environment, Vol. 19, No. 4, Pergamon Press, Great Britain, 1984 pp. 221-233

Sandberg, M. \& Blomqvist, C., "A Quantitative Estimate of the Accuracy of Tracer Gas Methods for the Determination of the Ventilation Flow Rate in Buildings,". Building and Environment, Vol. 20, No. 3, Pergamon Press, Great Britain, 1985, pp. 139-150

Sherman, M.H., "Variation-Induced Bias in Passive Ventilation Measurement," LBL-23088. Lawrence Berkeley Lab, U.C., Berkeley, CA. 1987

Sinden, F.W., "Multi-Chamber Theory of Air Infiltration," Building and Environment, Vol. 13, Pergamon Press, Great Britain, 1978 pp. 21-28

Turiel. I. \& Rudy, J., Occupant-Generated $\mathrm{CO}_{2}$ as an Indicator of Ventilation Rates, Lawrence Berkeley Lab, LBL10496, UC-95d, EEB-Vent 80-15, Berkeley, CA., 1980

Walker, R.R., "Interpretation and Error Analysis of Multiple-Tracer Gas Measurements to Determine Air Movements in a House," Proc. 6th AIVC Confer., Supplemental Proceedings: Ventilation Strategies and Measurement Techniques, Het Meerdal, Park, Netherlands, 1985

Walton, G.N., Estimating Interroom Contaminant Movements, NBSIR 85-3229,U.S. DOC, NBS, Gaithersburg, MD, August, 1985

Waters, J.R. \& Simons, M.W., "The Evaluation of Contaminant Concentrations and Air Flows in a Multizone Model of a Building,"Building and Environment, Vol. 22, No. 4, Pergamon Press, Great Britain, 1987 pp. $305-315$

Wen, C.Y., \& Fan, L.T., Models for Flow Systems and Chemical Reactors, Marcel Dekker, Inc., NY,NY, 1975

Westerterp, K.R., van Swaaji, W.P.M., \& Beenackers, A.A.C.M., Chemical Reactor Design and Operation. John Wiley \& Sons, New York, 1984 
MPS-IILA inEV. 20001

U.3. DEPT. OF COMn.

BIBLIOGRAPHIC DATA

SHEET (Soe in sivecions)

1. PUBLICATION OR
REPORT NO.
NISTIR $88-3855$

2. Performing Orsan. Report Nod 3. Publication Date

SEPTEMBER 1988

4. TITLE AND SUBTITLE

Integral Mass Balances and Pulse Injection Tracer Techniques

5. AUTHOR(S)

James Axley and Andrew Persily

6. PERFORMING ORGANIZATION (If joint or other thon NBS, see instructlons)

NATIONAL BUREAU OR STANDARDS

U.S. DEPARTMENT OF COMMERCE

GATTHERSBURG, MD 20899

9. SPONSORING ORGANIZATION NAME AND COMPLETE ADDRESS (Street, CIty. Stote, ZIP)

7. Contrace/Grant No.

8. Type of Report \& Period Covered

U.S. Department of Energy

Washington, D.C.

10. SUPPLEMENTARY NOTES

Document describes a computer program; SF-185, FIPS Software Summary, is attached.

11. ABSTRACT (A 200-word or less factual summory of most significont informotion. If document includes a significant bibliogrophy or literature survey, mention it here)

Tracer gas techniques for measuring airflow rates in building systems are considered. These techniques are classified in terms of tracer gas injection strategy employed and mass balance relationships used to analyze measured tracer concentration data. The discussion focuses on one class of tracer techniques - the pulse injection techniques based upon pulse injection strategies and integral mass balance relationships. These pulse injection techniques have not been comonly used in the past yet they provide practically useful means for the determination of airflow rates in building systems. Pulse injection techniques are presented for measuring airflows in ducts, and for studying single-zone and multi-zone building airflow systems. Experimental procedures for these three cases are discussed, and preliminary results from field applications of these techniques are presented. The possibility of flow variation is accounted for In all cases, and the sensitivity of the single-zone constant injection technique. This comparison leads to integral formulations of the constant injection technique for duct, single-zone, and multi-zone situations that may provide means to improve the accuracy of the commonly used constant injection tracer technique.

12. KEY WORDS (Six to twelve entries; olphobetical order; copitolize only proper nomes; ond seporote key words by scmicolons) bullding infiltration, bullding ventilation, tracer gas techniques, Integral mass balances.

13. AVAILABILITY

[D Unlimited

For Official Distribution. Do Not Release to NTIS

J. Order From Suderintendent of Documents, U.S. Govemment Printing Office, Washington, D.C. 20402.

* Order From National Technical Information Service (NTIS), Springfield, VA. 22161
14. NO. OF PRINTED PAGES

39

15. Price.

$\$ 11.95$ 
